Check for updates

Cite this: Environ. Sci.: Atmos., 2021, 1 , 434

Received 26th June 2021

Accepted 10th August 2021

DOI: $10.1039 / \mathrm{d} 1 \mathrm{ea} 00050 \mathrm{k}$

rsc.li/esatmospheres

\section{Molecular characterization of ultrafine particles using extractive electrospray time-of-flight mass spectrometry $\dagger$}

\author{
Mihnea Surdu, (D) $\ddagger^{a}$ Veronika Pospisilova, (ID $\ddagger \S^{a}$ Mao Xiao, ${ }^{a}$ Mingyi Wang, ${ }^{b}$ \\ Bernhard Mentler, ${ }^{c}$ Mario Simon, ${ }^{d}$ Dominik Stolzenburg, ${ }^{\text {eg }}$ Christopher R. Hoyle, ${ }^{\text {af }}$ \\ David M. Bell, (D) a Chuan Ping Lee, (D) a Houssni Lamkaddam, ${ }^{a}$ Felipe Lopez-Hilfiker, ${ }^{a}$ \\ Lauri R. Ahonen, ${ }^{9}$ Antonio Amorim, ${ }^{\mathrm{h}}$ Andrea Baccarini, (D) ai Dexian Chen, ${ }^{\mathrm{b}}$ \\ Lubna Dada, ${ }^{\text {ag }}$ Jonathan Duplissy, (D) ${ }^{\text {gj }}$ Henning Finkenzeller, ${ }^{\mathrm{k}} \mathrm{Xu}$-Cheng He, ${ }^{\mathrm{g}}$ \\ Victoria Hofbauer, ${ }^{\text {b }}$ Changhyuk Kim, ${ }^{\text {Im }}$ Andreas Kürten, ${ }^{d}$ Aleksandr Kvashnin, ${ }^{\circ}$ \\ Katrianne Lehtipalo, ${ }^{\text {gp }}$ Vladimir Makhmutov, ${ }^{\circ}$ Ugo Molteni, $q^{a}$ Wei Nie, ${ }^{9}$ Antti Onnela, ${ }^{n}$ \\ Tuukka Petäjä,, Lauriane L. J. Quéléver, ${ }^{9}$ Christian Tauber, ${ }^{e}$ António Tomé, \\ Robert Wagner, ${ }^{9}$ Chao Yan, ${ }^{9}$ Andre S. H. Prevot, ${ }^{a}{ }^{\prime}$ Josef Dommen, ${ }^{a}$ \\ Neil M. Donahue, (iD ${ }^{b}$ Armin Hansel, ${ }^{c}$ Joachim Curtius, ${ }^{d}$ Paul M. Winkler, ${ }^{e}$ \\ Markku Kulmala, (D) gj Rainer Volkamer, ${ }^{k}$ Richard C. Flagan,' Jasper Kirkby, ${ }^{\text {dn }}$ \\ Douglas R. Worsnop, ${ }^{\text {ss }}$ Jay G. Slowik, ${ }^{* a}$ Dongyu S. Wang, ${ }^{* a}$ Urs Baltensperger ${ }^{a}$ \\ and Imad el Haddad (iD) *a
}

\begin{abstract}
Aerosol particles negatively affect human health while also having climatic relevance due to, for example, their ability to act as cloud condensation nuclei. Ultrafine particles (diameter $D_{\mathrm{p}}<100 \mathrm{~nm}$ ) typically comprise the largest fraction of the total number concentration, however, their chemical characterization is difficult because of their low mass. Using an extractive electrospray time-of-flight mass spectrometer (EESI-TOF), we characterize the molecular composition of freshly nucleated particles from naphthalene and $\beta$-caryophyllene oxidation products at the CLOUD chamber at CERN. We perform a detailed intercomparison of the organic aerosol chemical composition measured by the EESI-TOF and an iodide adduct chemical ionization mass spectrometer equipped with a filter inlet for gases and aerosols (FIGAERO-I-CIMS). We also use an aerosol growth model based on the condensation of organic vapors to show that the chemical composition measured by the EESI-TOF is consistent with the expected condensed oxidation products. This agreement could be further improved by constraining the
\end{abstract}

${ }^{a}$ Laboratory of Atmospheric Chemistry, Paul Scherrer Institute, 5232 Villigen, Switzerland.E-mail: imad.el-haddad@psi.ch; dongyu.wang@psi.ch; jay.slowik@ psi.ch

${ }^{b}$ Center for Atmospheric Particle Studies, Carnegie Mellon University, 15213 Pittsburgh, PA, USA

'Institute of Ion Physics and Applied Physics, University of Innsbruck, 6020 Innsbruck, Austria

${ }^{d}$ Institute for Atmospheric and Environmental Sciences, Goethe University Frankfurt, 60438 Frankfurt am Main, Germany

${ }^{e}$ Faculty of Physics, University of Vienna, 1090 Vienna, Austria

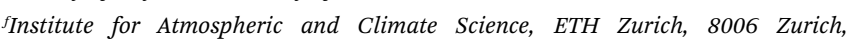
Switzerland

gInstitute for Atmospheric and Earth System Research (INAR)/Physics, Faculty of Science, University of Helsinki, 00014 Helsinki, Finland

${ }^{h}$ CENTRA, FCUL, University of Lisbon, 1749-016 Lisbon, Portugal

${ }^{i}$ School of Architecture, Civil and Environmental Engineering, École Polytechnique Fédérale de Lausanne, 1015 Lausanne, Switzerland

${ }^{j}$ Helsinki Institute of Physics, University of Helsinki, o0014 Helsinki, Finland

${ }^{k}$ Department of Chemistry, CIRES, University of Colorado Boulder, 80309 Boulder, CO, USA
${ }^{\prime}$ California Institute of Technology, Division of Chemistry and Chemical Engineering, 210-41, Pasadena, CA 91125, USA

${ }^{m}$ School of Civil and Environmental Engineering, Pusan National University, Busan 46241, Republic of Korea

${ }^{n}$ CERN, 1211 Geneva, Switzerland

${ }^{\circ} P$. N. Lebedev Physical Institute of the Russian Academy of Sciences, Laboratory of Solar and Cosmic Ray Physics, 119991 Moscow, Russia

${ }^{p}$ Finnish Meteorological Institute, 00560 Helsinki, Finland

${ }^{q}$ Joint International Research Laboratory of Atmospheric and Earth System Research, School of Atmospheric Sciences, Nanjing University, Nanjing, China

'IDL-Universidade da Beira Interior, 6201-001 Covilhã, Portugal

${ }^{s}$ Aerodyne Research, 01821 Billerica, MA, USA

$\dagger$ Electronic supplementary information (ESI) available. See DOI: $10.1039 / \mathrm{d} 1 \mathrm{ea} 00050 \mathrm{k}$

† These authors contributed equally to this work.

$\S$ Now at: Tofwerk AG, 3600 Thun, Switzerland.

I Now at: Forest Dynamics, Swiss Federal Institute for Forest, Snow and Landscape Research WSL, 8903 Birmensdorf, Switzerland; Department of Chemistry, University of California, 92697 Irvine, CA, USA. 
EESI-TOF compound-specific sensitivity or considering condensed-phase processes. Our results show that the EESI-TOF can obtain the chemical composition of particles as small as $20 \mathrm{~nm}$ in diameter with mass loadings as low as hundreds of $\mathrm{ng} \mathrm{m}^{-3}$ in real time. This was until now difficult to achieve, as other online instruments are often limited by size cutoffs, ionization/thermal fragmentation and/or semicontinuous sampling. Using real-time simultaneous gas- and particle-phase data, we discuss the condensation of naphthalene oxidation products on a molecular level.

\section{Introduction}

Atmospheric aerosols, solid or liquid particles suspended in air, can be primary, from direct emissions, or secondary, formed through gas-to-particle conversion of low-volatility vapours. Fine particles with a size of less than $1 \mu \mathrm{m}$ account for $50-70 \%$ of the total particulate matter mass under highly polluted environments. ${ }^{1}$ In particular, ultrafine particles (diameter $D_{\mathrm{p}}<$ $100 \mathrm{~nm}$ ) are suspected to pose a substantial health risk for humans due to their smaller size and thus higher body penetration $^{2}$ but are difficult to chemically characterize due to their low mass. A substantial fraction of the atmospheric particle number concentrations are created by new particle formation (NPF), which is thought to be a source for up to half of the global cloud condensation nuclei (CCN). ${ }^{3,4}$ The growth of nucleated particles to the CCN size is dominated by the condensation of low-volatility oxidation products from biogenic or anthropogenic precursors. Secondary organic aerosol (SOA) is a highly complex matrix of thousands of individual chemical species, the majority of which are present only in trace amounts. ${ }^{5}$ Moreover, rapid intra-particle reactions which increase the complexity of SOA and the need for their real-time measurement have been proposed and observed.,

While a variety of chemical ionization mass spectrometry (CIMS) techniques have been able to provide real time measurement of gas phase composition, no comparable techniques were available for real time particle-phase measurements until recently. For example, CIMS-based techniques used for atmospherically relevant mass concentrations (detection limits of $\mathrm{ng} \mathrm{m}^{-3}$ ), such as the Filter Inlet for Gases and Aerosols (FIGAERO), ${ }^{8}$ Thermal Desorption Chemical Ionization mass spectrometer (TDCIMS), ${ }^{9}$ or Thermal Desorption Differential Mobility Analyzer (TD-DMA) ${ }^{\mathbf{1 0}}$ require separate collection and analysis stages and are thus "quasi" real time. However, considering the sample collection time (>600 s), the time resolution of such techniques is a limitation for the identification of species responsible for the early stages of particle growth, as well as the detection of rapid intra-particle processes. Since they are based on thermal desorption, for these techniques thermal decomposition can also play a role, biasing measurements and complicating molecular identification. Nevertheless, they may provide additional physiochemical information such as aerosol volatility or size-resolved aerosol composition. Instruments like the Aerosol Mass Spectrometer (AMS) trade off the ability to be quantitative for extensive thermal and ionization-induced fragmentation due to high vaporisation temperature $\left(600{ }^{\circ} \mathrm{C}\right)$ and the use of electron ionization $(70 \mathrm{eV}) .{ }^{11}$ The AMS cut-off size of $\sim 60 \mathrm{~nm}$ also hinders its ability to characterize ultrafine particles. Additionally, the CHARON-PTR ("chemical analysis of aerosol online" inlet coupled to a proton transfer reaction timeof-flight mass spectrometer) ${ }^{\mathbf{1 2}}$ and the AeroFAPA-MS (aerosol flowing atmospheric-pressure afterglow mass spectrometer) ${ }^{\mathbf{1 3 , 1 4}}$ have been developed to provide online particle-phase measurements without the need for separate collection and analysis stages. Although these instruments have sufficiently low detection limits for atmospheric measurements, they are limited by cut-off size drawbacks (>100 nm) and ionization induced fragmentation for the CHARON-PTR and competing ionization pathways for the AeroFAPA-MS, leading to complicated spectral interpretation.

In response to these limitations, the extractive electrospray ionization time-of-flight mass spectrometer (EESI-TOF) ${ }^{\mathbf{1 5}}$ has been recently developed, providing online molecular-level chemical identification of OA at detection limits of several ng $\mathrm{m}^{-3}$, with minimal thermal and ionization-induced fragmentation. The EESI technique has been further advanced to allow for online tandem mass spectrometry (coupled to an Orbitrap mass analyser) and the characterization of water-soluble metals. ${ }^{16,17}$ The real-time capability of the EESI-TOF has enabled measurement of gas-to-particle partitioning in chamber studies and provided evidence of condensed-phase reactions. ${ }^{7,18}$

In this work, we used the EESI-TOF to study in real time the molecular composition of freshly nucleated particles from the oxidation of naphthalene or $\beta$-caryophyllene in the Cosmic Leaving OUtdoor Droplets (CLOUD) chamber at the European Organization for Nuclear Research (CERN). We determined the size and mass detection limits of the EESI-TOF and present a detailed intercomparison of the chemical composition measured with the EESI-TOF and FIGAERO-CIMS. Furthermore, we show that the measured particle composition is largely consistent with the condensation of the measured organic vapours as described by an aerosol growth model. Overall, we demonstrate that the EESI-TOF is well suited to study the composition of nanoparticles during their early growth.

\section{Methods}

\subsection{CLOUD chamber}

The measurements were carried out in the CLOUD chamber at CERN during the CLOUD11 campaign in fall 2016. The CLOUD chamber is a $26.1 \mathrm{~m}^{3}$ electropolished stainless steel chamber which enables experiments at atmospheric conditions with a very low background contamination. A schematic of the CLOUD chamber is shown in Fig. S1, $\dagger$ and it is described in detail by Kirkby et al. (2011) ${ }^{\mathbf{1 9}}$ as well as Duplissy et al. (2016). ${ }^{20}$ Ozone $\left(\mathrm{O}_{3}\right)$ is produced by flowing a small air flow past a quartz tube surrounded by UVC lamps (wavelength $<240 \mathrm{~nm}$ ). A UV 
light system, containing four $200 \mathrm{~W}$ Hamamatsu $\mathrm{Hg}$-Xe lamps (wavelength $250-450 \mathrm{~nm}$, adjustable power) and a $4 \mathrm{~W} \mathrm{KrF}$ excimer UV laser (wavelength $248 \mathrm{~nm}$ ), generates hydroxyl $(\mathrm{OH})$ radicals via $\mathrm{O}_{3}$ photolysis. To photolyse $\mathrm{NO}_{2}$ to NO, strong LEDs were used (wavelength $385 \mathrm{~nm}$ ). In order to avoid contamination, pure air was generated by the evaporation of cryogenic liquid nitrogen (Messer, 99.999\%) and liquid oxygen (Messer, $99.999 \%$ ) at a ratio of $79: 21$. This makes it possible to investigate aerosol nucleation and growth in a nearly contaminationfree environment. ${ }^{21}$ Relative humidity was controlled by flowing a fraction of the air through a Nafion ${ }^{\circledR}$ humidifier using ultrapure water (18 $\mathrm{M} \Omega \mathrm{cm}$, Millipore Corporation). Two Teflonvaned fans were mounted to the floor and ceiling of the chamber to ensure quick gas-phase mixing. The CLOUD chamber was operated in continuous flow mode. During typical experiments, a large suite of instrumentation is connected to the chamber to characterize gas- and/or particle-phase compounds spanning over wide volatility and/or size ranges. Gas-phase monitors measure the gas phase concentrations of $\mathrm{O}_{3}$ (Thermo Environmental Instruments TEI 49C), $\mathrm{SO}_{2}$ (Thermo Fisher Scientific Inc. 42i-TLE), NO (ECO 485 Physics, CLD 780TR) and $\mathrm{NO}_{2}$ (CAPS NO2, Aerodyne Research Inc.). A commercial nano SMPS (TSI 3938) with a water CPC (TSI 3788) measures the dry aerosol size distribution from $4.6 \mathrm{~nm}$ to $60 \mathrm{~nm}$. A home-built scanning mobility particle sizer (SMPS) with a differential mobility analyser (DMA) and a condensation particle counter (CPC, TSI 3010) measures the aerosol size distribution from $20 \mathrm{~nm}$ to $400 \mathrm{~nm}$.

\subsection{EESI-TOF}

The EESI-TOF setup used in these measurements is based on the setup of Lopez-Hilfiker et al. (2019). ${ }^{15}$ A backing pressure of 400 mbar was applied to the electrospray (ES) solution bottle, providing a flow of ES solution through a fused silica capillary with an inner diameter of $75 \mu \mathrm{m}$ (BGB Analytik AG, Boeckten, Switzerland). The EESI-TOF inlet temperature was kept constant at $250{ }^{\circ} \mathrm{C}$ throughout the experiments. A potential difference relative to the mass spectrometer interface in the range of 2.5-3 $\mathrm{kV}$ was applied to the ES solution to provide a stable ES signal. The ES working solution used was methanol/water $(50 / 50 \mathrm{v} / \mathrm{v})$, doped with $100 \mathrm{ppm}$ NaI. This ensures that the analyte ions are detected predominantly as sodiated adducts $\left([\mathrm{M}+\mathrm{Na}]^{+}\right)$in the positive ionization mode. Methanol/water ES solution may lead to an increased background signal (more detected ions from impurities) compared to more conventionally used acetonitrile (ACN)/water ES solution. ${ }^{15}$ However, it is better suited for the detection of organic nitrates compared to ACN/ water solvents, where $\mathrm{N}$-containing ions may correspond to $\mathrm{ACN}+\mathrm{Na}$ clusters. Previous studies on infusion ESI report reactions between methanol solvent and carbonyl analytes, e.g. yielding acetals/hemiacetals, which are shown to worsen with sample storage time (minutes-days). ${ }^{22}$ These reactions are not expected to be significant in our EESI system due to the much shorter extraction timescale (milliseconds). The HTOF mass analyzer of the EESI-TOF had a mass resolution of $\sim 4000-4500$ and was operated with $1 \mathrm{~s}$ time resolution with periodic filter blank measurements for 2 minutes every 13 minutes. EESI-TOF data were averaged to 10 seconds and background-corrected by subtracting filter blank measurements. As some of the fitted peaks in the EESI-TOF data may correspond to background contaminations from the inlet or the sampling lines, a data filter was applied to identify genuine analyte ion signals: time series of all EESI-TOF identified ions were correlated against total SMPS mass, and ions with an $R^{2}$ value of less than 0.7 were excluded. Each molecular formula was also checked manually to make sure that no ions that could correspond to genuine SOA peaks were excluded, and only time series belonging to contamination peaks were eliminated.

The EESI-TOF signal was converted to mass flux reaching the detector (in ag s ${ }^{-1}$ ), by scaling with the molecular weight of each molecule $i, \mathrm{MW}_{i}$, as follows:

$$
\operatorname{EESI}\left(\mathrm{ag} \mathrm{s}^{-1}\right)=\sum_{i} \frac{\operatorname{EESI}(\mathrm{Hz}) \times \mathrm{MW}_{i} \times 10^{18}}{N_{\mathrm{a}}}
$$

where $\operatorname{EESI}(\mathrm{Hz})$ is the signal directly measured by the TOF and $N_{\mathrm{a}}$ is Avogadro's number. The detection efficiency in the EESI-TOF is dependent on a variety of factors including mass transmission to the detector, extraction efficiency, particle size and ionization efficiency. As we do not yet have a complete understanding of the effect of these factors, we uniformly apply a bulk sensitivity factor to convert the EESI-TOF signals to mass concentrations. Since this sensitivity will depend on the status of the mass spectrometer, it is obtained by calibrating the total EESI mass flux $\left(\mathrm{ag} \mathrm{s}^{-1}\right)$ with the bulk aerosol mass from the SMPS for each experiment. The reported EESI signals are also normalized by the main reagent ion signal $\left(\mathrm{NaINa}^{+}\right)$to account for fluctuations in the electrospray stability during the different experimental runs.

\subsection{FIGAERO-CIMS}

The EESI-TOF measurements were compared to the particlephase measurements of a FIGAERO-CIMS, which measured both the gas- and particle-phase in alternating stages. During the gas-phase measurement stage, a separate sample stream with a flow rate of $6 \mathrm{~L} \mathrm{~min}^{-1}$ passed through a $24 \mathrm{~mm}$ diameter PTFE filter for particle collection for $\sim 50 \mathrm{~min}$. To initiate the particle desorption stage, the PTFE filter was transferred to the measurement line and $2.7 \mathrm{~L} \mathrm{~min}{ }^{-1}$ of pure $\mathrm{N}_{2}$ were heated progressively to thermally desorb and vaporise the collected particles. The pure $\mathrm{N}_{2}$ and thus the filter temperature increased from 20 to $150{ }^{\circ} \mathrm{C}$ at a rate of $\sim 10{ }^{\circ} \mathrm{C} \mathrm{min}^{-1}$. The desorption stage lasted for 14 minutes. In either stage, the gas-phase or desorbed analyte vapours were sampled into a $150 \mathrm{mbar}$ ion-molecule reactor and ionized by iodide $\left(\mathrm{I}^{-}\right)$ions generated by passing an $\mathrm{N}_{2}$ flow containing $\mathrm{CH}_{3} \mathrm{I}$, supplied using an inline permeation source, over a ${ }^{210}$ Po radioactive source. An LTOF mass analyser with a mass resolution of approximately 10000 was used for ion separation and detection. The organic analytes were detected predominantly in the form of iodide adducts $[\mathrm{M}+\mathrm{I}]^{-}$(>95\% relative abundance).

\subsection{Gas-phase mass spectrometers}

A proton transfer reaction mass spectrometer (PTR3-TOF-MS), described in detail by Breitenlechner et al. (2017), ${ }^{23}$ used 
proton-transfer or ligand-switching to measure the precursor concentrations as well as oxygenated volatile organic compounds (OVOCs). Highly oxygenated molecules (HOM) and sulphuric acid $\left(\mathrm{H}_{2} \mathrm{SO}_{4}\right)$ were measured using a nitrate chemical ionization atmospheric pressure interface time-of-flight mass spectrometer (Nitrate-CI-APi-TOF), described in detail by Kürten et al. (2014), ${ }^{24}$ using nitrate anions $\left(\left(\mathrm{HNO}_{3}\right)_{n}\left(\mathrm{NO}_{3}{ }^{-}\right)\right.$, with $n=0-2)$ as reagent ions.

\subsection{Estimated volatility parametrizations}

The saturation vapour concentration of organic compounds from naphthalene oxidation, $C^{*}$ was estimated using the parametrization described in detail by Wang et al. ${ }^{25}$ based on FIGAERO-CIMS measurements,

$$
\log _{10} C_{300}^{*}=\left(n_{\mathrm{C}}^{0}-n_{\mathrm{C}}\right) b_{\mathrm{C}}-n_{\mathrm{O}} b_{\mathrm{O}}
$$

where $C_{300}^{*}$ is the saturation vapour concentration at $300 \mathrm{~K}$ in $\mu \mathrm{g}$ $\mathrm{m}^{-3} ; n_{\mathrm{C}}$ is the number of carbon atoms of the molecule, $n_{\mathrm{C}}^{0}=25$ based on the reference carbon number of pure hydrocarbons with $C^{*}=1 \mu \mathrm{g} \mathrm{m}^{-3}$. On average, each carbon addition decreases $\log _{10} C_{300}^{*}$ by $b_{\mathrm{C}}=0.48$. Additionally, functional groups decrease $\log _{10} C_{300}^{*}$ and are parameterized in the formula by the effective oxygen number $\left(n_{\mathrm{O}}\right)$. A nitrate group $\left(-\mathrm{ONO}_{2}\right)$ normally reduces $\log _{10} C_{300}^{*}$ by 2.5 , so for simplicity the nitrate group was counted as -OH. Therefore, the effective oxygen number $n_{\mathrm{O}}$ was calculated as the oxygen number subtracted by twice the nitrogen number. For SOA originated from naphthalene oxidation, $b_{\mathrm{O}}=$ 1.72 is applied based on FIGAERO measurements. ${ }^{25}$

\subsection{Aerosol growth model}

We modelled particle growth based on the measured gas-phase concentrations of the oxidation products and their estimated volatilities, as described by Xiao et al. ${ }^{26}$ When combining the gas phase concentrations from the two mass spectrometers, signals from the PTR3 were used for monomers with a low degree of oxygenation $\left(n_{\mathrm{C}} \leq 10, n_{\mathrm{O}} \leq 5\right)$ whereas signals from the $\mathrm{NO}_{3}$ CIMS were used for all compounds with $n_{\mathrm{O}} \geq 6$. Signals from analyte clusters with $\left(\mathrm{NO}_{3}\right)^{-}$and $\mathrm{HNO}_{3}\left(\mathrm{NO}_{3}\right)^{-}$were summed up when obtaining the concentrations from the $\mathrm{NO}_{3}$-CIMS. Compounds measured in the gas phase by PTR3 and $\mathrm{NO}_{3}$-CIMS were grouped into volatility bins according to the VBS framework. ${ }^{27}$

Using the measured gas-phase concentrations grouped into volatility bins, the particle-phase is modelled similar to the works of Stolzenburg et al. (2018) and Tröstl et al. (2016) as follows. ${ }^{28,29}$ The driving force of gas to particle partitioning of each VBS bin is described as:

$$
F_{i}=C_{\mathrm{g}, i}-C_{\mathrm{eq}, i}
$$

where $C_{\mathrm{g}, i}$ is the measured gas-phase concentration of the $i^{\text {th }}$ VBS bin and $C_{\text {eq }, i}$ is the equilibrium concentration of the $i^{\text {th }}$ VBS bin. Mass or volume growth was modelled for aerosol particles with diameters above $6 \mathrm{~nm}$, as the mass of particles below $6 \mathrm{~nm}$ is negligible. So, for simplicity we exclude the Kelvin term (which accounts for the curvature effect of very small particles).
Hence, $C_{\mathrm{eq}, i}=\chi_{i} C_{i}^{*}$, where $\chi_{i}$ is the activity. Assuming that the particle phase is an ideal solution, it follows that $\chi_{i}=C_{\mathrm{p}, i} / C_{\mathrm{p}, \text { tot }}$, which is the ratio of the particle mass in the $i^{\text {th }}$ bin $\left(C_{\mathrm{p}, i}\right)$ to the total particle mass $\left(C_{\mathrm{p} \text {,tot }}\right)$. Sulphuric acid was allowed to condense at the kinetic limit in the growth model.

The gas to particle condensation flux can be described as:

$$
\phi_{i}=K_{i} F_{i}
$$

As we only model growth for aerosols with a diameter above $6 \mathrm{~nm}$ and thus ignore the Kelvin effect, the condensation rate $K_{i}$ is approximated by the condensation sink of the aerosol population:

$$
K_{i}=\sum 2 \pi \beta D N_{\mathrm{p}} D_{\mathrm{p}}
$$

where $\beta=(\mathrm{Kn}+1) /\left(0.377 \mathrm{Kn}+1+\frac{4}{3 a_{i}} \mathrm{Kn}^{2}+\frac{4}{3 a_{i}} \mathrm{Kn}\right)$ is the correction factor for non-continuum dynamics; $\mathrm{Kn}$ is the Knudsen number; $D$ is the diffusion coefficient of the gas molecule, estimated experimentally by Reid et al. (1987); ${ }^{30} N_{\mathrm{p}}$ is the number concentration of particles at diameter $D_{\mathrm{p}}$.

Therefore, the volume growth of aerosol can be described as:

$$
\frac{\mathrm{d} V}{\mathrm{~d} t}=\sum_{i} \phi_{i} V_{i}-\left(k_{\mathrm{dil}}+k_{\text {wall }}\right) V
$$

where $V$ is the total particle volume; $k_{\mathrm{dil}}$ is the chamber dilution rate $\left(k_{\text {dil }}=1.6 \times 10^{-4} \mathrm{~s}^{-1}\right)$ and $k_{\text {wall }}$ is the particle wall loss rate.

We obtained the growth of aerosol particles in volume by solving the equations describing the gas-to-particle partitioning process.

\section{Results and discussion}

As the CLOUD project focuses mainly on new particle formation and growth, the mass concentrations in the chamber are generally low $\left(<10 \mathrm{ng} \mathrm{m}^{-3}\right)$. Therefore, the EESI-TOF mostly operated very close to its detection limits. ${ }^{15}$ A series of experiments, including $\beta$-caryophyllene ozonolysis and naphthalene oxidation, were dedicated for particle-phase measurement by extending the growth period to achieve final aerosol concentrations of 400-800 $\mathrm{ng} \mathrm{m}^{-3}$. Experimental conditions are given in Table 1.

\subsection{Proof-of-principle measurements of naphthalene and $\beta$ - caryophyllene SOA at CLOUD}

To evaluate the suitability of the EESI-TOF to measure the composition of nanoparticles during early growth, we analysed the EESI-TOF response for a series of experiments of naphthalene oxidation by $\mathrm{OH}$ radicals, in the presence of $\mathrm{NO}_{x}$, a system characteristic of polluted urban areas. ${ }^{32}$ Fig. 1a shows the particle size distribution during a typical nucleation and growth experiment at CLOUD (experiment 1). The experiment shown in Fig. 1a includes particles initiated from 2 growth events; it is not possible to separate the contribution from each event, since the EESI-TOF does not provide size resolved data. Nevertheless, the 
Table 1 List of experimental conditions for the experiments from the CLOUD 11 campaign analysed throughout this work. Mixing ratios refer to the values before the start of the oxidation

\begin{tabular}{|c|c|c|c|c|c|c|c|c|c|}
\hline $\begin{array}{l}\text { Experiment } \\
\text { number }\end{array}$ & Precursor & $\begin{array}{l}\text { Precursor mixing } \\
\text { ratio (ppbV) }\end{array}$ & $T\left({ }^{\circ} \mathrm{C}\right)$ & RH (\%) & $\begin{array}{l}\text { Peak OA mass } \\
\text { (approx.) }\left(\mathrm{ng} \mathrm{m}^{-3}\right)\end{array}$ & $\begin{array}{l}\mathrm{NO}_{x} \\
(\mathrm{ppbV})\end{array}$ & $\begin{array}{l}\text { Ozone } \\
\text { (ppbV) }\end{array}$ & $\mathrm{SO}_{2}(\mathrm{ppbV})$ & $\mathrm{NH}_{3}(\mathrm{ppbV})$ \\
\hline 1 & Naphthalene & 10 & 20 & 80 & 800 & 5 & 40 & 1 & 1.2 \\
\hline 3 & $\begin{array}{l}\beta- \\
\text { Caryophyllene }\end{array}$ & 0.4 & 5 & 40 & 400 & 0 & 40 & 0 & 0 \\
\hline
\end{tabular}

mean volume-weighted particle diameter, as calculated by the SMPS, ranges between 20-60 $\mathrm{nm}$ throughout the entire experiment.

During this experiment, naphthalene oxidation product monomers $\left(n_{\mathrm{C}}=8,9,10\right.$, red) and dimers $\left(n_{\mathrm{C}}=20\right.$, blue) are observed by the EESI-TOF, shown in Fig. $1 \mathrm{~b}$, as the SOA mass concentration increases to $\sim 800 \mathrm{ng} \mathrm{m}^{-3}$. As shown in Fig. 1c, while EESI-TOF and FIGAERO-CIMS show good agreement in the general trend of naphthalene oxidation products, as exemplified by $\mathrm{C}_{10} \mathrm{H}_{10} \mathrm{O}_{5,7}$, the EESI-TOF is able to provide a more time-resolved description. In total, for this experiment we identified 125 ions (96 monomers and 29 dimers) out of which 33 were nitrogen-containing ( 27 monomers and 6 dimers) using the EESI-TOF, as well as 168 ions (120 monomers and 48 dimers) out of which 63 nitrogen-containing (47 monomers and
21 dimers) using the FIGAERO-CIMS. For experiment 1, 33 identical ions were detected by the EESI-TOF and FIGAEROCIMS. The correlation of the trend of these common ions is given in Fig. S2. $\dagger$ Overall, the intensity of the common ions accounts for $46 \%$ of the total EESI-TOF intensity and $36 \%$ of the total FIGAERO-CIMS intensity (at maximum aerosol mass). A full mass spectrum of the identified ions, for 5 minutes at the period of maximum aerosol mass from experiment 1 , is given in Fig. 1d. The particle-phase composition as measured by the EESI-TOF is consistent with the compounds found in the gas phase from the Nitrate-CIMS (Fig. S3†), as well as previous work on gas-phase naphthalene oxidation products. ${ }^{33,34}$

Additionally, the corresponding online measurements of the molecular composition of freshly nucleated SOA from naphthalene and $\beta$-caryophyllene, both in the absence of $\mathrm{NO}_{x}$
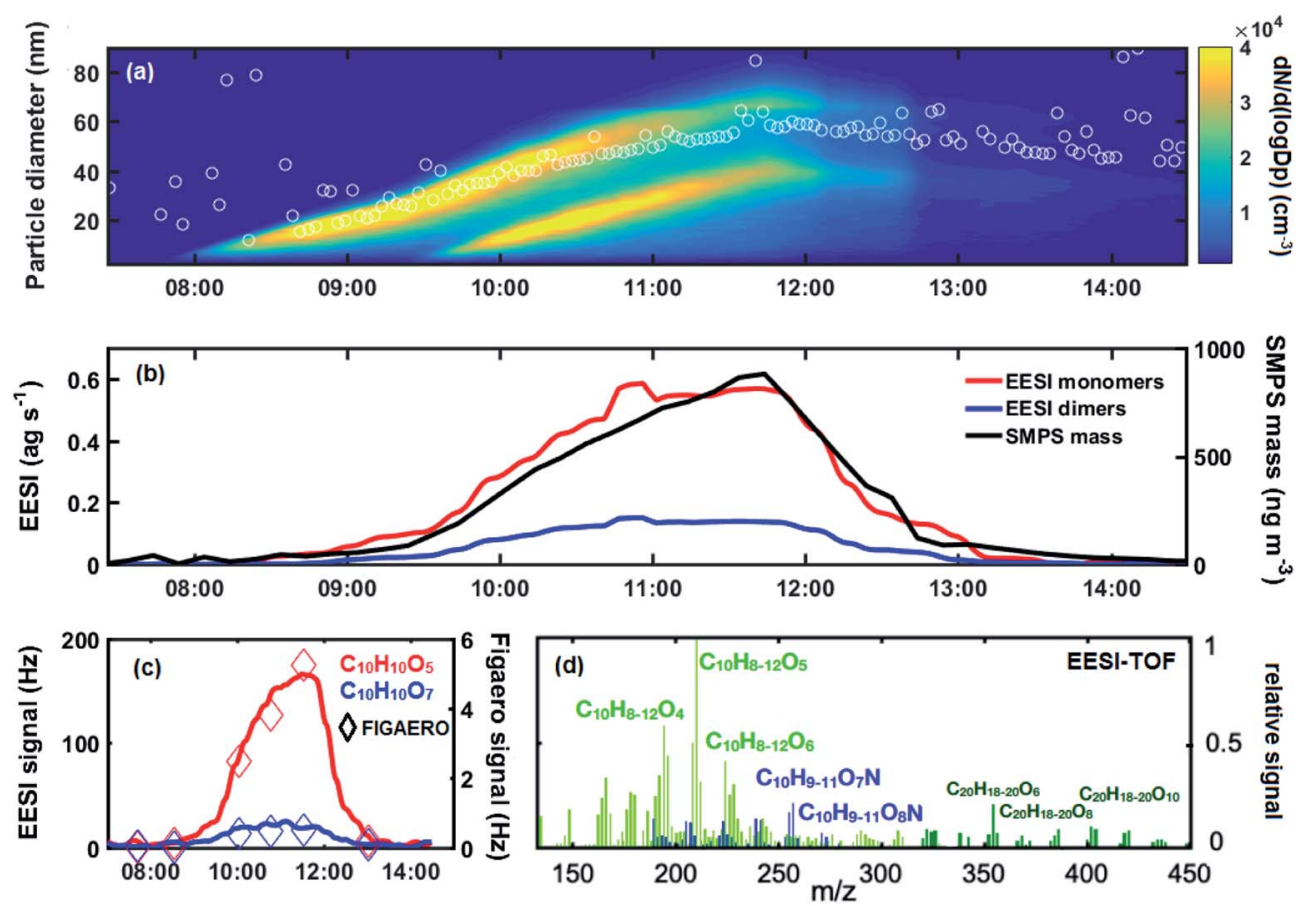

Fig. 1 (a) Combined nano-SMPS and SMPS number-weighted size distribution for experiment 1 during the CLOUD 11 campaign. Mean volumeweighted particle diameter in white circles. The excimer UV laser was switched on at 09:20 AM, leading to a 2nd growth event. (b) Time evolution of sum of the monomer (sum of C8, C9 and C10 compounds) and dimer (C20) oxidation products from naphthalene measured by the EESI-TOF together with the total mass measured by the SMPS. (c) Particle-phase time evolution of $\mathrm{C}_{10} \mathrm{H}_{10} \mathrm{O}_{5,7}$ species as products from naphthalene photo-oxidation measured by the EESI-TOF (lines) and FIGAERO-I-CIMS (diamonds) from experiment 1. (d) Mass spectrum of EESI-TOF naphthalene oxidation products from experiment 1 . Signals are normalized to the most intense peak. Monomer compounds are coloured in light green, nitrogen-containing compounds in blue and dimers in dark green. 
(experiments 2 and 3) are shown in Fig. S4 and S5, $\uparrow$ respectively. We observe excellent correlations $\left(R^{2}>0.93\right)$ between the mass detected by the EESI and the bulk SOA mass determined from the SMPS for all experiments (Fig. S6 $\dagger$ ). The calibration factor varies between experiments as it is dependent on both instrumental settings as well the SOA composition.

The intercomparison of EESI-TOF and FIGAERO-CIMS in Fig. 2 shows significant overlap, adding confidence to the molecular speciation of the organic aerosol responsible for nucleation and early growth of nanoparticles. Both instruments indicate that $\mathrm{C}_{9-10}$ compounds with 8 or less oxygen atoms dominate the particle phase spectra. In the EESI-TOF, $\mathrm{C}_{11}$ compounds only account for $1-2 \%$ of the total, suggesting that reactions between methanol in the electrospray solution and $\mathrm{C}_{10}$ compounds (yielding acetals/hemiacetals from carbonyls) ${ }^{22}$ are negligible. This is also consistent with the good agreement between EESI-TOF and FIGAERO-CIMS in terms of carbon number distribution in the monomer region, where the FIGAERO-CIMS is not affected by such reactions. We also observe good agreement in the oxygen distribution measured by the EESI-TOF and FIGAERO-CIMS, particularly for $\mathrm{C}_{10}$ compounds. In addition, both instruments observe smaller compounds $\left(\mathrm{C}_{5-8}\right)$. Many of these, e.g. $\mathrm{C}_{5-8} \mathrm{H}_{6-14} \mathrm{O}_{3-9}$, are also present in the gas-phase as measured by PTR3 and/or nitrateCIMS. It is possible that these are authentic naphthalene oxidation products or fragmentation artefacts, given their
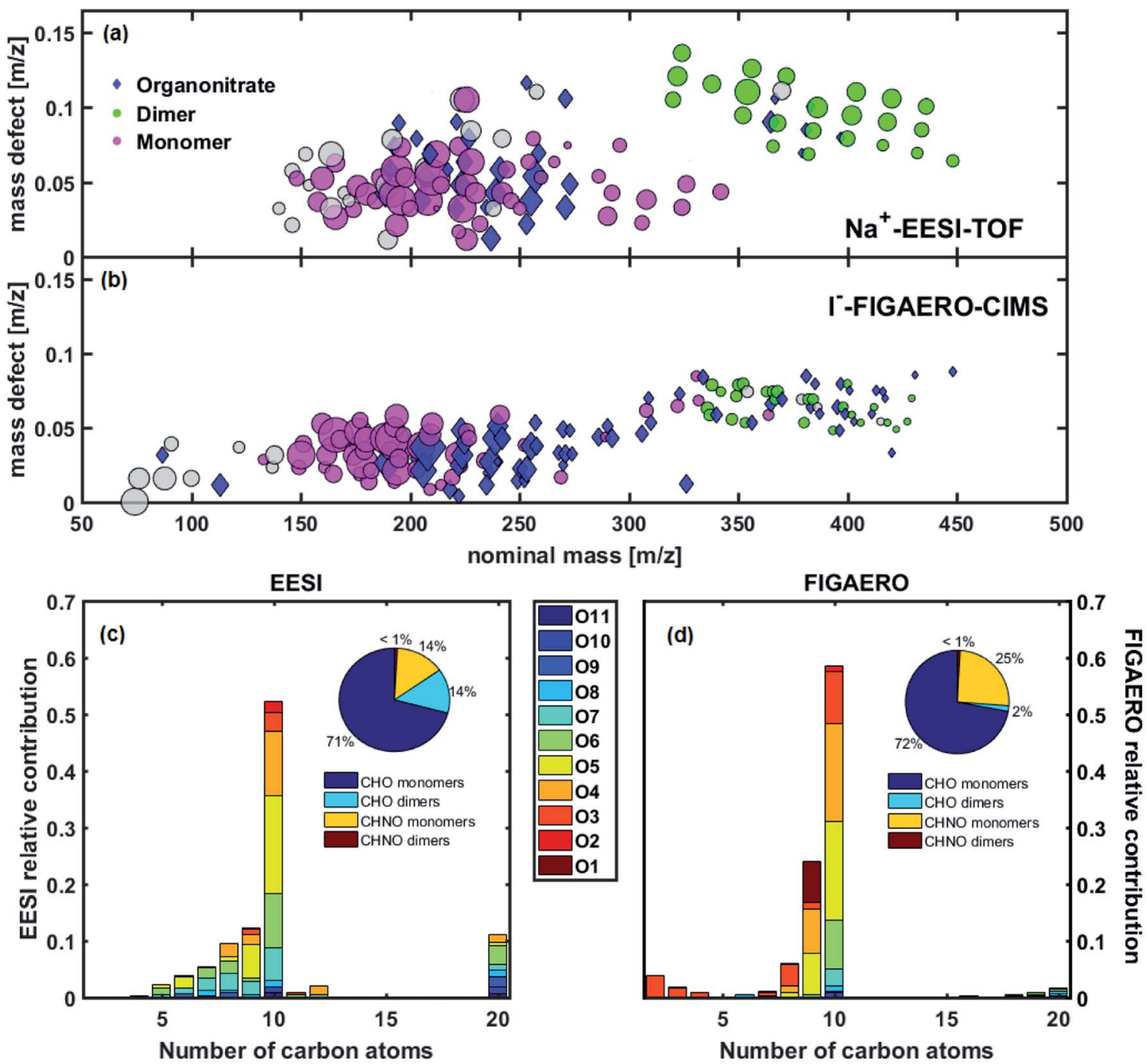

Fig. 2 (a and b) Molecular composition of naphthalene oxidation products (experiment 1). Mass defect (difference of exact mass to integer mass) versus $\mathrm{m} / \mathrm{z}$ of particle-phase products as detected by (a) the $\mathrm{Na}^{+}$-EESI-TOF and (b) the $\mathrm{I}^{-}$-FIGAERO-CIMS. Marker area is sized by square root of ion intensity. Each marker represents the molecular composition of a particular detected ion, with the reagent ion it is clustered to $\left(\mathrm{Na}^{+} / I^{-}\right)$ removed. Markers are coloured and shaped by their chemical formula. Markers are categorized according to the following criteria: organonitrates (blue diamonds) are any $\mathrm{N}$ containing compounds; monomers (pink circles) are $\mathrm{C}_{8-10}$ compounds; dimers (green circles) are $\mathrm{C}_{17-20}$ compounds. All other identified compounds have grey circle markers. (c and d) Comparison of the molecular distribution of particle phase naphthalene oxidation products measured by the EESI-TOF (c) and FIGAERO-CIMS (d) at maximum aerosol mass. The absolute signal of each measured ion is binned by carbon number and coloured by oxygen number. Nitrogen-containing compounds are shown together with nonnitrogen-containing species. The fractional contributions to the total aerosol signal of nitrogenated and non-nitrogenated monomers and dimers in the FIGAERO-CIMS and EESI-TOF are shown in insets. 
relatively high volatility. Whereas the FIGAERO-CIMS (equipped with an LTOF) reported $\mathrm{C}_{16-20}$ dimers, we preferentially assigned the EESI-TOF peaks in the dimer region $(\mathrm{m} / \mathrm{z}>300)$ to $\mathrm{C}_{20}$ compounds, given the lower mass resolution of the HTOF mass analyzer coupled to the EESI.

Overall, the signal corresponding to dimers is higher in the EESI-TOF than the FIGAERO-CIMS $(13 \%$ of the total particlephase signal, Fig. 2c, compared to $2 \%$ for the FIGAERO-CIMS, Fig. 2d). This could be due to several reasons. First, it is possible that the FIGAERO-CIMS suffers from thermal decomposition fragmentation ${ }^{28,35,36}$ of these (extremely) low-volatility compounds due to the higher temperature needed to desorb them from the filter. This possibility would agree with the observation that less oxygenated compounds $\left(\mathrm{O}_{1}-\mathrm{O}_{3}\right)$ are more abundant in the FIGAERO-CIMS spectra, which could correspond to the fragments as they are unlikely to condense. Here we have not performed a thermogram analysis to identify and correct for any possible thermal decomposition artefacts. Moreover, $[2 \mathrm{M}+\mathrm{Na}]^{+}$clusters could also form during ionization in the EESI-TOF, elevating the observed dimer fraction. As these clusters are typically minor $\left(0.1-1 \%\right.$ of $\left.[\mathrm{M}+\mathrm{Na}]^{+}\right)$and difficult to distinguish from authentic dimers without the use of a declustering scan, we did not attempt to correct for this potential artefact. Finally, this inconsistency could also arise from other instrumental differences such as differing compound-specific sensitivity, mass transmission, different ionization mechanisms, and more.

Another discrepancy in the SOA composition measured by the two instruments is the lower fraction of nitrogen-containing species observed in the EESI-TOF (16\% compared to $26 \%$ in the FIGAERO-CIMS). Also, despite the lower dimer fraction measured by the FIGAERO-CIMS, a higher number of nitrogencontaining dimers (24) was detected, compared to 6 in the EESITOF. Many of these nitrogen-containing species have low intensities and we assume that a large fraction of these species fall below the detection limits of the EESI-TOF. Further, it has been shown that hydroxynitrates can lose $\mathrm{HNO}_{3}$ during the ionization process in the EESI-TOF, ${ }^{18}$ leading to their classification as non-nitrogenated compounds, though it is not clear how nitrogen containing functional groups would behave in aromatic systems. Regardless, dimers containing nitrogen contribute less than $1 \%$ to the total aerosol signal in both instruments and as such do not affect the main findings from the studied system.

Fig. $\mathrm{S} 7 \dagger$ shows the chemical composition for naphthalene SOA without the addition of $\mathrm{NO}_{x}$ (experiment 2), from both the EESI-TOF and the FIGAERO-CIMS. As expected, nitrogencontaining species are almost completely absent in the experiment without $\mathrm{NO}_{x}$, with only minor peaks detected, most likely due to the high background level of those ions from previous experiments. Additionally, $\mathrm{NO}_{x}$ also appear to suppress dimers in the particle phase: a considerably smaller dimer fraction is measured in the presence of $\mathrm{NO}_{x}$ by both the EESI-TOF $(14 \%$ with $\mathrm{NO}_{x}, 21 \%$ without) and FIGAERO-CIMS ( $2 \%$ with $\mathrm{NO}_{x}, 4 \%$ without). This is consistent with previous studies showing a reduction of the dimer fraction by $\mathrm{NO}_{x}$ in the gas-phase and consequently in the particle phase for both biogenic and anthropogenic SOA. ${ }^{25,37}$

For the $\beta$-caryophyllene system (Fig. S8 $\dagger$ ), the two instruments also show a good agreement, with C15 compounds making up the bulk of the detected ions. Similar to the naphthalene system, smaller compounds are also detected in both the EESI-TOF and the FIGAERO-CIMS. Both instruments agree that the dimer fraction is lower for the $\beta$-caryophyllene system as compared to the naphthalene system. It is possible that the relative dimer fraction will be smaller for $\beta$-caryophyllene as monomers are able to partition to the particle phase to a greater extent. This is because of the higher carbon number for $\beta$-caryophyllene $\left(\mathrm{C}_{15}\right)$ compared to naphthalene $\left(\mathrm{C}_{10}\right)$ and thus lower volatility (despite lower $\mathrm{O}: \mathrm{C}$ ratio). It is also possible that $\mathrm{RO}_{2}$ radicals with less functionalization (lower $\mathrm{O}: \mathrm{C}$ ratio) of $\beta$-caryophyllene could have lower accretion reaction rates than the more functionalized (higher $\mathrm{O}: \mathrm{C}$ ) $\mathrm{RO}_{2}$ from naphthalene. This observation would agree with the previous study of Berndt et al. (2017). ${ }^{38}$

Quantitatively, a good agreement is also observed between the intensities of the ion signals (at maximum aerosol mass) in the EESI-TOF and the FIGAERO-CIMS. For the compounds that were detected by both instruments in experiment 1 , this relationship is shown in Fig. S9. $\dagger$ While the sensitivity towards different compounds in both instruments is expected to vary slightly, the respective detected intensities for any species are always within an order of magnitude, suggesting good general agreement. Overall, there appears to be considerable overlap in the chemical composition of the SOA measured by both instruments for the SOA investigated here.

\subsection{EESI-TOF size-resolved detection limits}

The 2 minute limit-of-detection of the EESI-TOF (LOD) was calculated as three times the standard deviation of background measurements, while universal sensitivity was applied for all ions in each SOA system. This is an estimate and disregards iondependant sensitivities. The universal sensitivity was calculated by calibrating the total EESI mass flux (ag $\mathrm{s}^{-1}$ ) with the bulk aerosol mass from the SMPS (using a density of $1.4 \mathrm{~g} \mathrm{~cm}^{-3}$ ) for experiments 1 and 3, resulting in sensitivities of 0.0017 and $0.0047 \mathrm{ag} \mathrm{s}^{-1} \mathrm{ng}^{-1} \mathrm{~m}^{3}$ for naphthalene and $\beta$-caryophyllene SOA respectively (Fig. S6†). A two-minute time period when the air passed via the particle filter of the EESI-TOF was considered as background measurement for the calculation of the LODs.

Estimated detection limits for the main ions observed by the EESI-TOF in the naphthalene and $\beta$-caryophyllene SOA systems are shown in Fig. 3a, on an ion-by-ion basis as a function of $m / z$. The LOD for all detected ions is less than $10 \mathrm{ng} \mathrm{m}^{-3}$, with similar detection limits for naphthalene and $\beta$-caryophyllene SOA. Lower $\mathrm{m} / \mathrm{z}$ compounds appear to have higher detection limits than larger, less volatile compounds such as dimers. As the signals determined by the EESI-TOF are calculated by subtracting the periodic filter blanks, the ion-specific background during these filter blank periods is crucial for accurate signal determination. During the filter measurement period, semivolatile compounds adsorbed to the inlet walls may 

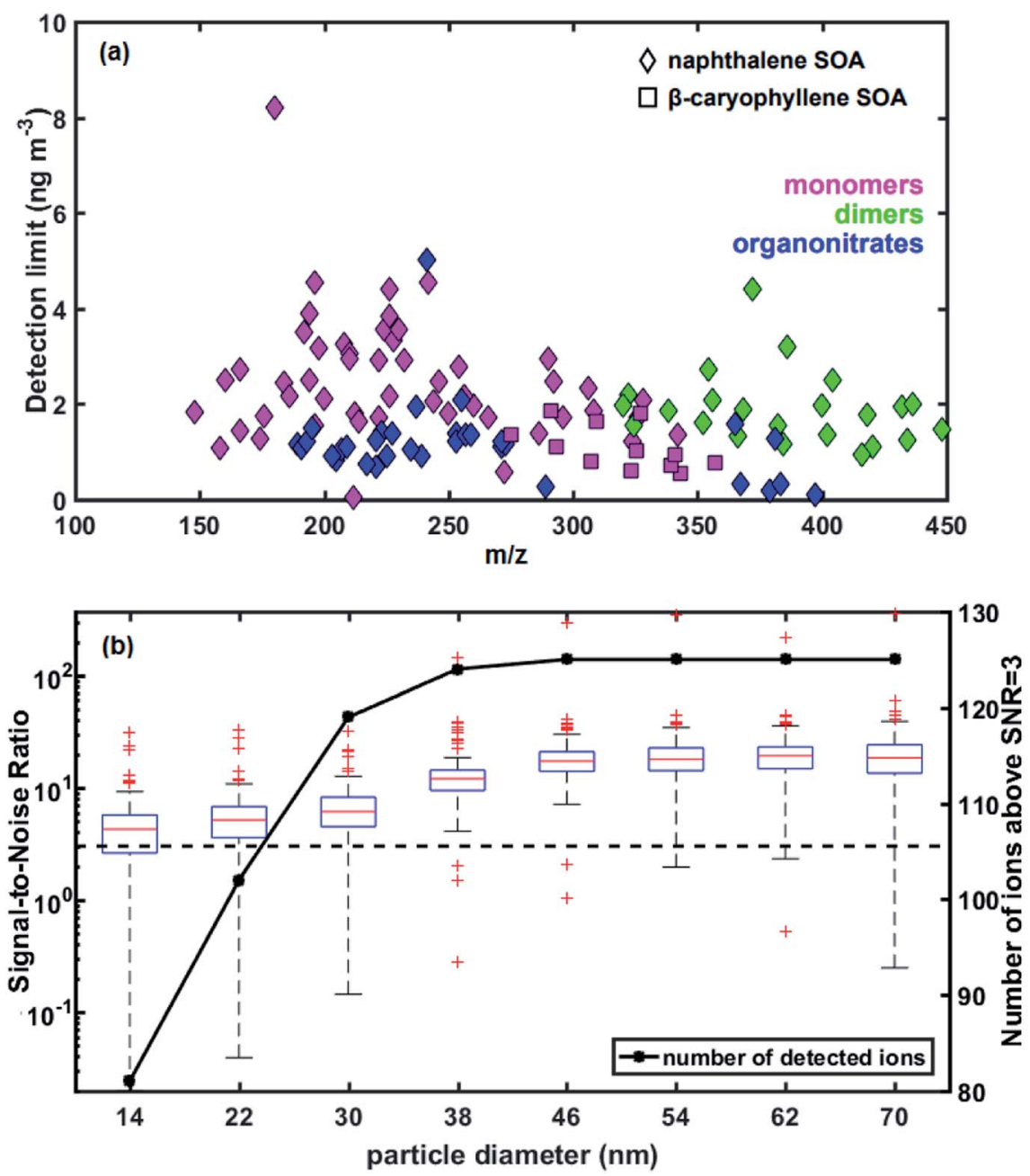

Fig. 3 (a) Limit of detection ( $3 \sigma$ of the 2 minute filter blank period, $10 \mathrm{~s}$ post-averaged data) of naphthalene and $\beta$-caryophyllene oxidation products. (b) Box and whisker plot of signal-to-noise ratio (SNR, left axis) as a function of geometric mean volume-based particle diameter for naphthalene SOA. Red central mark represents the median, bottom and top edges of the box represent the 25th and 75th percentiles, respectively while the black dashed lines extend to the furthest values not considered outliers. Outliers are plotted individually using red ' + ' markers. SNR $=3$ shown as dashed black line. The number of detected ions with SNR above three as a function of particle diameter are shown as a solid black line (right axis).

repartition back to the gas phase, causing an elevated background compared to the low-volatility compounds, which would result in a lower signal reported than expected. Another possibility for the increased background in the filter period is gas breakthrough in the denuder. Although the charcoal denuder is $>99 \%$ efficient in removing the gas phase, ${ }^{15}$ the EESI-TOF has a much higher sensitivity for the gas-phase than the particlephase, ${ }^{39}$ meaning that even a relatively small amount of gas breakthrough could elevate the background of the filter period. Some ions show a small step change in the background levels as gas-phase concentrations increased, suggesting that at least some ions are affected by gas-phase breakthrough. However, as particle growth follows immediately after the increase in gasphase concentrations, it is difficult to differentiate between the effects of vapor-wall interactions and denuder breakthrough.

We characterize the detection limits of the EESI-TOF as a function of particle size in order to assess its ability to study freshly nucleated particles (Fig. 3b). The EESI-TOF followed the evolution of the particle size distribution during experiment 1 , therefore detecting different particle sizes at different times. The signal-to-noise ratio (SNR) was calculated as the ratio of the signal to the noise as follows; similar to the LOD calculation, a two-minute filter blank period during the experiment was chosen as the background level. The signal was defined as a continuous time series of the background-corrected ion intensity observed by the EESI-TOF while the noise was defined as:

$$
\text { Noise }=\sqrt{\frac{\sigma_{\mathrm{bkg}}{ }^{2}}{n_{\mathrm{bkg}}}}
$$

where $\sigma$ is the standard deviation and $n$ is the number of data points. The majority of detected ions (119 ions, $97 \%$ of total ion signal at maximum mass) are above SNR $=3$ for particle diameters as small as $30 \mathrm{~nm}$, corresponding to a total OA mass 
of $\sim 100 \mathrm{ng} \mathrm{m} \mathrm{m}^{-3}$. Since just a few species dominate the particle phase signal, we are also able to reliably detect the key chemical species contributing to particle growth for particle diameters as small as $14 \mathrm{~nm}$. For example, 81 ions, corresponding to $80 \%$ of total ion signal at maximum mass, are detectable above $\mathrm{SNR}=3$ at such particle size and mass. These results show that the EESITOF can accurately characterize the chemical composition of ultrafine particles in real-time, with sufficiently low detection limits on the order of $\mathrm{ng} \mathrm{\textrm {m } ^ { - 3 }}$ to fully characterize the chemical composition at aerosol loadings of a few hundreds of $\mathrm{ng} \mathrm{m}^{-3}$.

\subsection{Study of aerosol growth using the EESI-TOF for naphthalene SOA}

We used a VBS-based approach to model aerosol growth based on the gas-phase concentrations of sulphuric acid and organic condensable vapours measured with the PTR-MS and the Nitrate-CIMS. Fig. 4 (and Fig. S10†) shows the modelled particle mass as well as the measured particle-phase concentrations from the EESI-TOF, grouped according to estimated volatility: extremely low volatility organic compounds (ELVOCs), low volatility organic compounds (LVOCs), semi-volatile organic compounds (SVOCs) and intermediate volatility organic compounds (IVOCs).

As in our previous study, ${ }^{26}$ we observe an excellent agreement between the modelled particle mass and the actual particle mass as measured by the SMPS (Fig. S10†). In Fig. 4, we compare the observed and predicted organic mass fractions. Modelled particle-phase sulphate mass is subtracted from the measured particle mass concentration (by the SMPS) for comparison with the EESI-TOF, since condensed-phase sulphate species undergo $\mathrm{Na}^{+}$exchange during the EESI-TOF ionization process, forming $\left[\mathrm{Na}_{2} \mathrm{SO}_{4}+\mathrm{Na}\right]^{+}$instead of simple $\mathrm{Na}$ adducts (e.g. $\left.\left[\mathrm{H}_{2} \mathrm{SO}_{4}+\mathrm{Na}\right]^{+}\right)$, and was therefore not included in the quantitative chemical composition analysis. We also obtain a good overall agreement between the predicted particlephase composition from the condensation of gas-phase species and the measured particle-phase composition from the EESITOF. For comparison, EESI-TOF signals were converted to estimated mass by calibrating the mass flux reaching the detector of the EESI-TOF against the total organic mass, therefore assuming uniform sensitivity for all measured components.

Since the aerosol growth model is strongly dependent on the estimated volatilities of the gas-phase oxidation products, we explored a range of parametrizations from previous studies (Fig. S11 $\dagger)^{25,27,28}$ The original Donahue et al. $(2011)^{27}$ VBS parametrization, developed before the role of autoxidation in SOA was appropriately appreciated, attributes oxygen atoms to $=\mathrm{O}$ and $-\mathrm{OH}$ functional groups, which decreases the saturation vapor pressure more than - $\mathrm{OOH}$. This leads to an underestimation of volatility when autoxidation predominates the organic oxidation mechanism, and therefore results in an overestimation of the ELVOC and LVOC fractions. Stolzenburg et al. $(2018)^{28}$ adapted the parametrization to include the increased fraction of hydroperoxide $(-\mathrm{OOH})$ products from autoxidation as well as covalently-bound dimers, both commonly found in $\alpha$-pinene SOA. Wang et al. (2020) ${ }^{25}$ used direct FIGAERO measurements of volatility to demonstrate that both parametrizations are valid, depending on the relevant chemistry: aromatics such as naphthalene lie close to the original parametrization, whereas biogenics such as terpenes lie close to the "autoxidation" parametrization. However, in
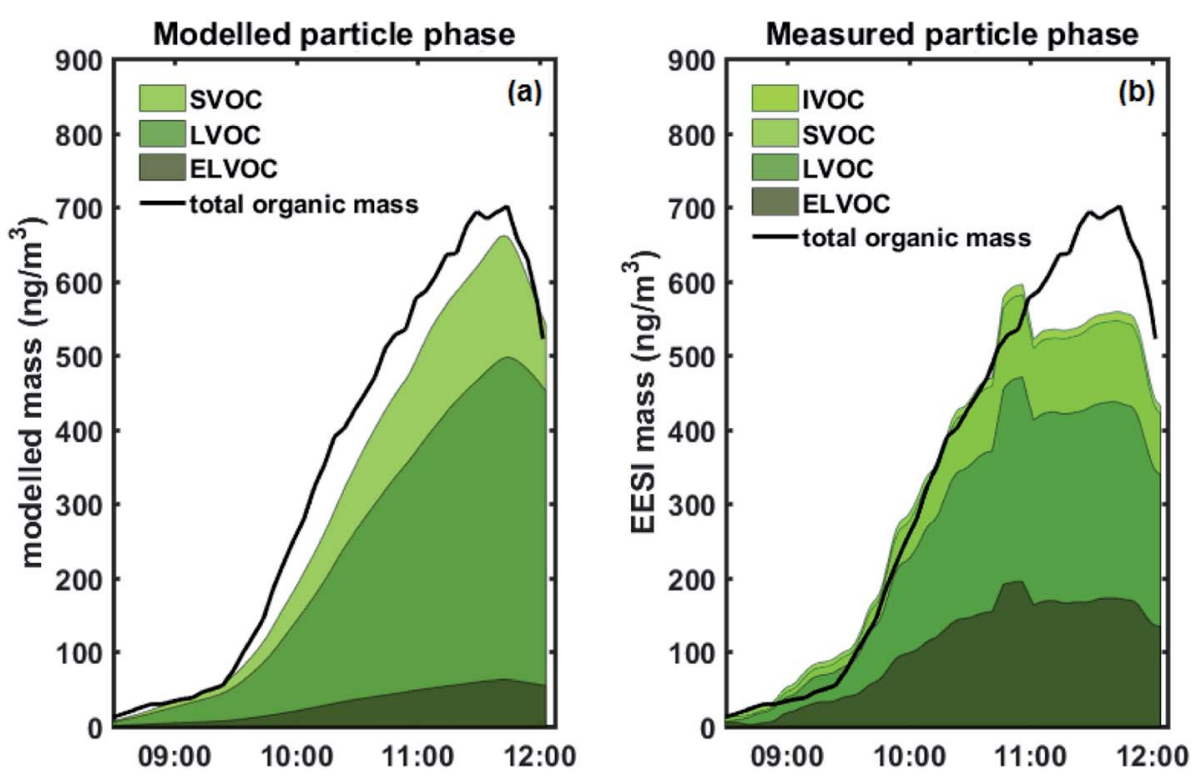

Fig. 4 (a) Stacked modelled particle mass (above $6 \mathrm{~nm}$ ) of total, ELVOC, LVOC, SVOC particle-phase naphthalene oxidation products. The ELVOC bin is an overflow bin and thus contains all compounds with $\log C^{*}<-4.5$. Total organic mass, calculated as measured SMPS mass minus modelled sulphate mass, overlaid as solid black line. (b) Stacked measured concentrations of total, ELVOC, LVOC, SVOC, IVOC particle-phase naphthalene oxidation products from the EESI-TOF, assuming uniform response factor. The ELVOC bin is an overflow bin and thus contains all compounds with $\log C^{*}<4.5$. Total organic mass, calculated as measured SMPS mass minus modelled sulphate mass, overlaid as solid black line. 
each case the direct measurements provide an updated, directly measured, parametrization. The sensitivity of aerosol growth model results to volatility parametrization methods is shown in Fig. S12. $\dagger$ Note that the parametrization of Wang et al. $(2020)^{25}$ is based on FIGAERO volatility measurements for this particular naphthalene SOA system, so this is the most relevant parametrization for this case and is used for the growth model unless specified otherwise.

Fig. 5a shows a quantitative comparison of the different volatility classes from the growth model and measured by the EESI-TOF. The modelled results show that initial growth (before 08:15 AM) is dominated by ELVOCs (Fig. 5b). As some of the detected compounds are still under the detection limit of the EESI-TOF at the lowest mass concentrations, the EESI-TOF data is only shown for mass concentrations greater than $\sim 50 \mathrm{ng} \mathrm{m}^{-3}$.
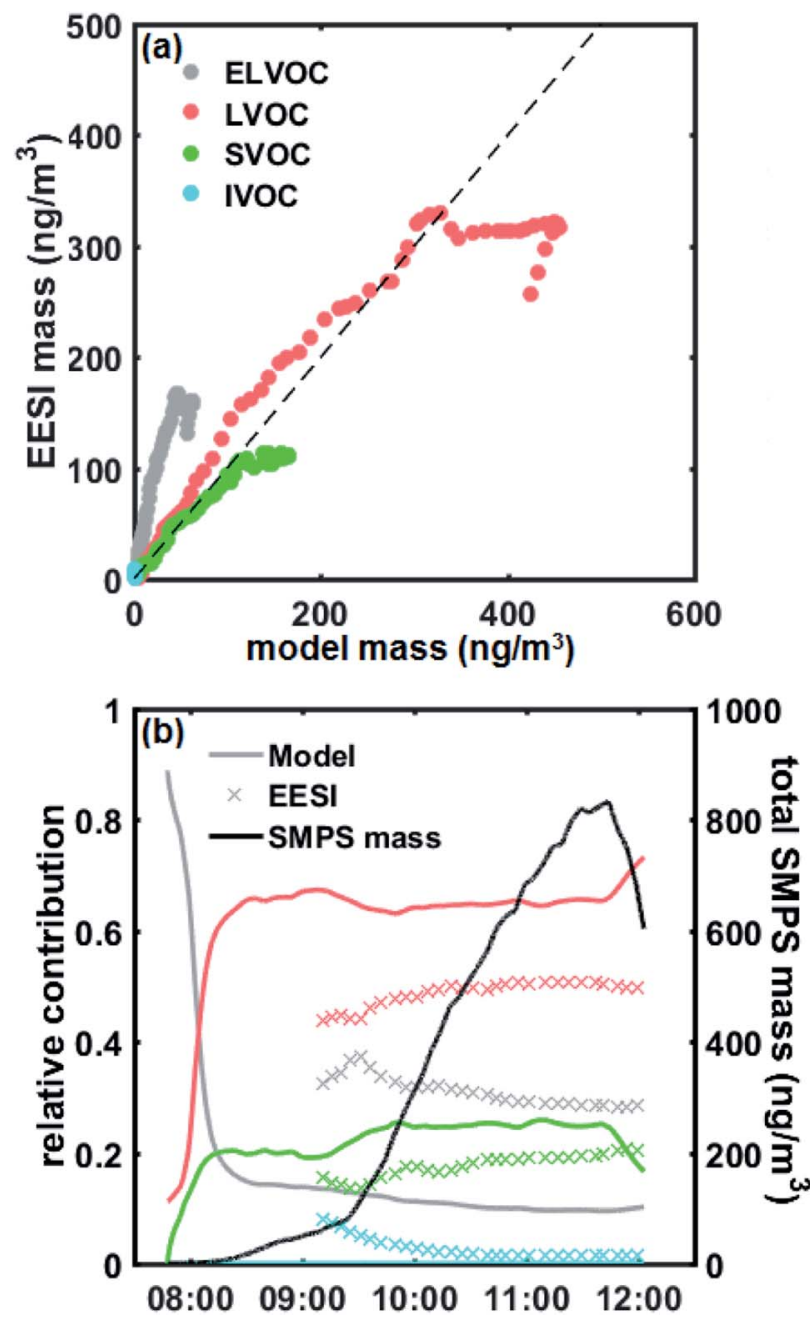

Fig. 5 (a) Correlation plot between the mass of different volatility classes (ELVOC, LVOC, SVOC, IVOC) from the aerosol growth model and measured by the EESI-TOF. $1: 1$ line shown as dashed black line. The ELVOC bin is an overflow bin and thus contains all compounds with $\log C^{*}<4.5$. (b) Fractional contributions of different volatility classes (colour-coded as in (a)) to total aerosol mass from the growth model (solid lines) and EESI-TOF (crosses). SMPS mass overlaid as solid black line. Note that sulphuric acid (SA) was not included in the contribution.
Both the modelled and measured results consistently show that the contribution from more volatile compounds such as LVOCs and SVOCs becomes more significant as particle mass increases (Fig. 5b), with LVOCs being the most abundant compound class for this experiment. A good agreement between the modelled and measured LVOC and SVOC fractions is seen, however, ELVOCs seem to be more abundant in the EESI-TOF data than we would expect from the condensation of the gas-phase. One explanation for the discrepancy of the ELVOC fraction could be due to the assumption of uniform sensitivity in the EESI-TOF when converting signals to estimated mass concentrations, which may be too simplistic. The EESI-TOF sensitivity has been shown $^{31}$ to increase with increasing molecular weight and oxygen content (e.g. $\left.n_{\mathrm{C}} n_{\mathrm{O}} /\left(n_{\mathrm{C}}+n_{\mathrm{O}}\right)\right)$, and therefore inversely correlate with $\log C^{*}$ (i.e. higher sensitivity for lower volatility compounds). Finally, we cannot rule out the possibility of condensed-phase reactions taking place which have not been considered in the aerosol growth model. The SOA composition has previously been observed to change after condensation; ${ }^{6,7}$ in particular, accretion reactions (e.g. $\left.\mathrm{C}_{7-10}+\mathrm{C}_{7-10}=>\mathrm{C}_{14-20}\right)^{40}$ would lead to an increase in the ELVOC fraction observed by the EESI which had not been taken into account in the model. However, due to the relatively short timescale of the experiment as well as the fact that all of the particle-phase compound concentrations appear to increase simultaneously in the EESITOF as the gas phase oxidation product concentrations increased, we are not able to distinguish such condensed-phase processes here. Interestingly, in the measured EESI-TOF data we also observe a small IVOC fraction that is not predicted by the growth model, which may be caused by gas-phase compounds breaking through the denuder - as the particle mass increases the relative contribution of this fraction decreases as the gasphase source is rather constant. We note that although the denuder is highly efficient at removing the gas phase $(>99 \%),{ }^{15}$ even a small amount of gas-phase breakthrough could be observed as the EESI-TOF is highly sensitive to gaseous compounds. $^{39}$ Nevertheless, overall our observations are consistent with the previous work of Tröstl et al. $(2016)^{29}$ which shows increasing contribution of higher volatility organics with increasing particle mass/size.

Fig. 6 shows a more detailed comparison between the particle phase composition measured by the EESI-TOF, the predicted particle phase composition from the aerosol growth model and the gas phase measured by the PTR3 and the nitrateCIMS. Since the condensation was modelled on a volatility-bin basis rather than compound-by-compound, the ratio of compounds corresponding to each bin in the condensed phase was assumed to be the same as in the gas phase. This was then multiplied by each integrated bin concentration to estimate the concentrations of each chemical species. Both the measured and modelled particle-phases are evidently less volatile and have higher average carbon oxidation state $\left(\mathrm{OS}_{\mathrm{C}}\right.$, calculated as 2 $\times \mathrm{O} / \mathrm{C}-\mathrm{H} / \mathrm{C}$ ) than the gas phase. When comparing the ultra-low volatility compounds (ULVOC) and ELVOC compounds where there were differences between the EESI-TOF data and the expected condensation of the gas-phase oxidation products, we observe that the modelled abundance of these compounds lies 

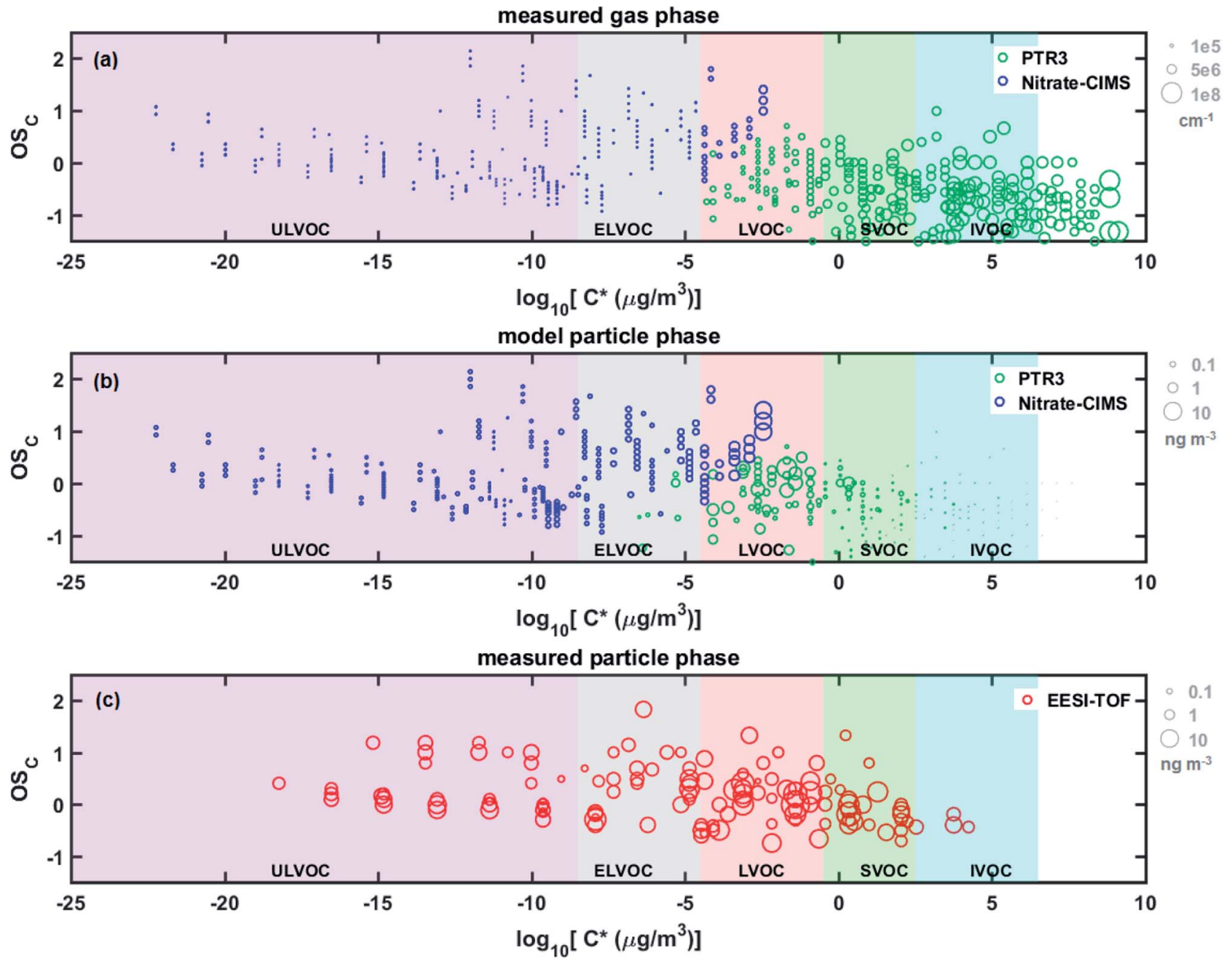

Fig. 6 Two-dimensional volatility basis set (2D-VBS) of naphthalene oxidation products. Compounds are plotted as carbon oxidation states $\left(\mathrm{OS}_{\mathrm{C}}\right)$ versus estimated volatility $\left(\log _{10} C^{*}\right)$ and sized by the square root of their intensity. Markers are coloured according to the measurement instrument. Shaded areas indicate the volatility ranges of ultra-low volatility (ULVOC, purple), extremely-low volatility (ELVOC, grey), lowvolatility (LVOC, red), semi-volatile (SVOC, green), intermediate volatility (IVOC, blue) and volatile (VOC, unshaded). (a) Measured gas phase naphthalene oxidation products, (b) modelled particle phase naphthalene oxidation products, (c) measured particle phase naphthalene oxidation products.

in between the observations from the FIGAERO-CIMS and EESITOF (Fig. S13†). As discussed before, the discrepancies may be due to compound-specific sensitivity differences between the instruments and potential thermal decomposition in the FIGAERO-CIMS.

At the molecular level, Fig. 6 shows that some ULVOCs with $\log _{10} C^{*}$ values less than -17 are noticeably absent in the EESITOF data. These highly oxygenated compounds $\left(n_{\mathrm{O}}>10\right)$ are only present at very low concentrations which are most likely under the detection limit of the EESI-TOF. Modelled and measured time series of such highly oxygenated dimer molecules are shown in Fig. S14. $\dagger$ The more volatile compounds in the EESI-TOF $\log C^{*}=2-4$ bins (see also Fig. S13 may expect in the particle phase in lower amounts given the model results and the low OA mass $\left(\sim 800 \mathrm{ng} \mathrm{m}^{-3}\right)$, correspond mainly to $\mathrm{C}_{10} \mathrm{H}_{x} \mathrm{O}_{3-4} \mathrm{~N}_{0-1}$ (Fig. S14†). While we do not exclude that denuder breakthrough or ionization-induced fragmentation artefacts could contribute to these signals, a change in their estimated volatility would also result in a large change in their expected particle phase contribution. Fig. S15† exemplifies the change in their partitioning coefficient, calculated as the modelled growth normalized to growth at the kinetic limit, when adjusting the estimated volatility by 1-2 orders of magnitude. Roughly speaking, an order of magnitude change in estimated $C^{*}$ would result in an order of magnitude change in their partitioning coefficient. Such a change in the estimated volatility is quite reasonable given the unknown nature of the functional group of the oxygen atoms - a hydroxyl group is predicted to decrease $\log C^{*}$ by 2.23 whereas a hydroperoxide group would only decrease $\log C^{*}$ by 1.24 per oxygen. ${ }^{41}$ While $b_{\mathrm{O}}=1.72$ used in the growth model based on FIGAERO measurements, ${ }^{25}$ such slightly oxygenated compounds, especially under high- $\mathrm{NO}_{x}$ conditions which suppress peroxy radical autoxidation, may have undergone only $-\mathrm{OH}$ addition resulting 
in a lower than predicted volatility. Lastly, fragmentation occurring in the PTR3 for such $\mathrm{C}_{10} \mathrm{H}_{x} \mathrm{O}_{3-4} \mathrm{~N}_{0-1}$ signals may be quite significant, ${ }^{\mathbf{4 2 , 4 3}}$ resulting in lower observed gas-phase concentrations and therefore lower expected particle-phase mass concentrations from the aerosol growth model.

Overall, we show that the particle composition measured by the EESI-TOF is in good agreement with the predicted particle composition from the condensation of gas-phase species, as well as that measured by the FIGAERO-CIMS. Uncertainties lie mainly in the compound-specific sensitivities in the EESI-TOF and the possibility of condensed-phase reactions taking place which have not been included in the aerosol growth model.

\section{Conclusion}

We presented a proof-of-concept application of the EESI-TOF at the CLOUD chamber at CERN, providing online measurements of the molecular composition of freshly nucleated nanoparticles from naphthalene and $\beta$-caryophyllene SOA. We offered a detailed intercomparison of the chemical composition measured with the EESI-TOF to the FIGAERO-CIMS. We demonstrated that the EESI-TOF can provide chemical composition measurement in real-time of particles as small as $20 \mathrm{~nm}$ and at mass loadings on the order of hundreds of $\mathrm{ng} \mathrm{m}^{-3}$, and therefore suitable for the study of growth under pristine atmospheric conditions. This has not been possible until now, as other online instruments such as the AMS or CHARON-PTR utilize aerodynamic lens-based systems with higher diameter cut offs. The FIGAERO and TD-DMA coupled to a CIMS are semi-continuous measurement techniques which may struggle to compete with the high time resolution required for nucleation experiments. By comparing our measurements to an aerosol growth model, we showed the consistency between the condensation of organic vapors and the measured particle phase. More work is required to fully understand observed differences, such as constraining the compound-specific response factors in the EESI-TOF or considering the possibility of condensed-phase processes in the aerosol growth model. The demonstrated capabilities of EESI-TOF enable the investigation of reactions occurring on rapid timescales, such as gas-to-particle partitioning or intra-particle reactions on a molecular level.

\section{Author contributions}

V. P., M. X., M. W., B. M., M. Sim., D. S., C. R. H., F. L.-H., L. R. A., A. A., A. B., L. D., J. Dup., C. K., J. K., K. L., V. M., B. M., U. M., W. N., L. L. J. Q., C. T., A. T., P. M. W. collected the data. V. P., M. X., M. W., B. M., M. Sim., D. S., C. R. H., F. L.-H., A. B., U. B., D. C., L. D., J. Dup., H. F., R. C. F., X.-C. H., V. H., C. K., J. K., A. Kür., A. Kvas., K. L., V. M., B. M., U. M., T. P., L. L. J. Q., A. T., R. W., P. M. W., C. Y., I. E.-H. prepared the CLOUD facility or measuring instruments. M. Sur., V. P., M. X., M. W., B. M., M. Sim., D. S., C. K., U. M. analyzed the data. M. Sur., V. P., M. X., M. W., D. S., D. M. B., C. P. L., H. L., H. F., U. M., J. K., M. Sim., D. R. W., A. S. H., J. Dup, J. Dom., N. M. D., A. H., J. C., M. K., R. C. F., R. V., J. G. S., D. S. W., U. B., I. E.-H. contributed to the scientific discussion and interpretation of results. $M$. Sur., V. P., J. Dom., D. S. W., U. B., I. E.-H. participated in writing the manuscript.

\section{Conflicts of interest}

There are no conflicts to declare.

\section{Acknowledgements}

We thank the European Organization for Nuclear Research (CERN) for supporting CLOUD with important technical and financial resources. We would also like to thank P. Carrie, L.-P. De Menezes, F. Josa, I. Krasin, O. S. Maksumov, I. Krasin, R. Sitals and A. Wasem for their contribution to the experiment. This research has received funding from the European Union's Horizon 2020 research and innovation programme under the Marie Sklodowska-Curie grant agreement no. 895875 ("NPFPANDA"), no. 764991 ("CLOUD-MOTION H2020-MSCA-ITN2017"), Swiss National Science Foundation (grant numbers 200021_169090, 200020_172602 and 20FI20_172622), the US National Science Foundation (NSF-AGS-1649147, NSF-AGS1801574, NSF-AGS-1801897, NSF-AGS-1531284 NSF 1602086, NSF 1801329), the Wallace Research Foundation, the NASA graduate fellowship (NASA-NNX16AP36H), the Portuguese Foundation for Science and Technology (CERN/FIS-COM/0014/ 2017) as well as the ERC Consolidator Grant "NANODYNAMITE" (No. 616075). We acknowledge the following projects: ACCC Flagship funded by the Academy of Finland (grant no. 337549), Academy professorship funded by the Academy of Finland (grant no. 302958), Academy of Finland projects no. 1325656, 316114 and 325647, "Quantifying carbon sink, CarbonSink+ and their interaction with air quality" INAR project funded by Jane and Aatos Erkko Foundation, European Research Council (ERC) project ATM-GTP Contract No. 742206.

\section{References}

1 Z. Wu, M. Hu, P. Lin, S. Liu, B. Wehner and A. Wiedensohler, Particle number size distribution in the urban atmosphere of Beijing, China, Atmos. Environ., 2008, 42, 7967-7980.

2 D. E. Schraufnagel, The health effects of ultrafine particles, Exp. Mol. Med., 2020, 52, 311-317.

3 J. Merikanto, D. V. Spracklen, G. W. Mann, S. J. Pickering and K. S. Carslaw, Impact of nucleation on global CCN, Atmos. Chem. Phys., 2009, 9, 8601-8616.

4 H. Gordon, J. Kirkby, U. Baltensperger, F. Bianchi, M. Breitenlechner, J. Curtius, A. Dias, J. Dommen, N. M. Donahue, E. M. Dunne, J. Duplissy, S. Ehrhart, R. C. Flagan, C. Frege, C. Fuchs, A. Hansel, C. R. Hoyle, M. Kulmala, A. Kürten, K. Lehtipalo, V. Makhmutov, U. Molteni, M. P. Rissanen, Y. Stozkhov, J. Tröstl, G. Tsagkogeorgas, R. Wagner, C. Williamson, D. Wimmer, P. M. Winkler, C. Yan and K. S. Carslaw, Causes and importance of new particle formation in the present-day and preindustrial atmospheres, J. Geophys. Res.: Atmos., 2017, 122, 8739-8760. 
5 A. H. Goldstein and I. E. Galbally, Known and Unexplored Organic Constituents in the Earth's Atmosphere, Environ. Sci. Technol., 2007, 41, 1514-1521.

6 A. Mutzel, L. Poulain, T. Berndt, Y. Iinuma, M. Rodigast, O. Böge, S. Richters, G. Spindler, M. Sipilä, T. Jokinen, M. Kulmala and H. Herrmann, Highly Oxidized Multifunctional Organic Compounds Observed in Tropospheric Particles: A Field and Laboratory Study, Environ. Sci. Technol., 2015, 49, 7754-7761.

7 V. Pospisilova, F. D. Lopez-Hilfiker, D. M. Bell, I. E. Haddad, C. Mohr, W. Huang, L. Heikkinen, M. Xiao, J. Dommen, A. S. H. Prevot, U. Baltensperger and J. G. Slowik, On the fate of oxygenated organic molecules in atmospheric aerosol particles, Sci. Adv., 2020, 6, eaax8922.

8 F. D. Lopez-Hilfiker, C. Mohr, M. Ehn, F. Rubach, E. Kleist, J. Wildt, T. F. Mentel, A. Lutz, M. Hallquist, D. Worsnop and J. A. Thornton, A novel method for online analysis of gas and particle composition: description and evaluation of a Filter Inlet for Gases and AEROsols (FIGAERO), Atmos. Meas. Tech., 2014, 7, 983-1001.

9 J. N. Smith, K. F. Moore, F. L. Eisele, D. Voisin, A. K. Ghimire, H. Sakurai and P. H. McMurry, Chemical composition of atmospheric nanoparticles during nucleation events in Atlanta, J. Geophys. Res.: Atmos., 2005, 110, D22S03.

10 A. C. Wagner, A. Bergen, S. Brilke, C. Fuchs, M. Ernst, J. Hoker, M. Heinritzi, M. Simon, B. Bühner, J. Curtius and A. Kürten, Size-resolved online chemical analysis of nanoaerosol particles: a thermal desorption differential mobility analyzer coupled to a chemical ionization time-offlight mass spectrometer, Atmos. Meas. Tech., 2018, 11, 5489-5506.

11 M. R. Canagaratna, J. T. Jayne, J. L. Jimenez, J. D. Allan, M. R. Alfarra, Q. Zhang, T. B. Onasch, F. Drewnick, H. Coe, A. Middlebrook, A. Delia, L. R. Williams, A. M. Trimborn, M. J. Northway, P. F. DeCarlo, C. E. Kolb, P. Davidovits and D. R. Worsnop, Chemical and microphysical characterization of ambient aerosols with the aerodyne aerosol mass spectrometer, Mass Spectrom. Rev., 2007, 26, 185-222.

12 P. Eichler, M. Müller, B. D'Anna and A. Wisthaler, A novel inlet system for online chemical analysis of semi-volatile submicron particulate matter, Atmos. Meas. Tech., 2015, 8, 1353-1360.

13 M. Brüggemann, E. Karu, T. Stelzer and T. Hoffmann, RealTime Analysis of Ambient Organic Aerosols Using Aerosol Flowing Atmospheric-Pressure Afterglow Mass Spectrometry (AeroFAPA-MS), Environ. Sci. Technol., 2015, 49, 5571-5578.

14 M. Brüggemann, L. Poulain, A. Held, T. Stelzer, C. Zuth, S. Richters, A. Mutzel, D. van Pinxteren, Y. Iinuma, S. Katkevica, R. Rabe, H. Herrmann and T. Hoffmann, Real-time detection of highly oxidized organosulfates and BSOA marker compounds during the F-BEACh 2014 field study, Atmos. Chem. Phys., 2017, 17, 1453-1469.

15 F. D. Lopez-Hilfiker, V. Pospisilova, W. Huang, M. Kalberer, C. Mohr, G. Stefenelli, J. A. Thornton, U. Baltensperger, A. S. H. Prevot and J. G. Slowik, An extractive electrospray ionization time-of-flight mass spectrometer (EESI-TOF) for online measurement of atmospheric aerosol particles, Atmos. Meas. Tech., 2019, 12, 4867-4886.

16 C. P. Lee, M. Riva, D. Wang, S. Tomaz, D. Li, S. Perrier, J. G. Slowik, F. Bourgain, J. Schmale, A. S. H. Prevot, U. Baltensperger, C. George and I. El Haddad, Online Aerosol Chemical Characterization by Extractive Electrospray Ionization-Ultrahigh-Resolution Mass Spectrometry (EESI-Orbitrap), Environ. Sci. Technol., 2020, 54, 3871-3880.

17 S. Giannoukos, C. P. Lee, M. Tarik, C. Ludwig, S. Biollaz, H. Lamkaddam, U. Baltensperger, A. S. H. Prevot and J. Slowik, Real-Time Detection of Aerosol Metals Using Online Extractive Electrospray Ionization Mass Spectrometry, Anal. Chem., 2020, 92, 1316-1325.

18 X. Liu, D. A. Day, J. E. Krechmer, W. Brown, Z. Peng, P. J. Ziemann and J. L. Jimenez, Direct measurements of semi-volatile organic compound dynamics show near-unity mass accommodation coefficients for diverse aerosols, Nat. Commun. Chem., 2019, 2, 1-9.

19 J. Kirkby, J. Curtius, J. Almeida, E. Dunne, J. Duplissy, S. Ehrhart, A. Franchin, S. Gagné, L. Ickes, A. Kürten, A. Kupc, A. Metzger, F. Riccobono, L. Rondo, S. Schobesberger, G. Tsagkogeorgas, D. Wimmer, A. Amorim, F. Bianchi, M. Breitenlechner, A. David, J. Dommen, A. Downard, M. Ehn, R. C. Flagan, S. Haider, A. Hansel, D. Hauser, W. Jud, H. Junninen, F. Kreissl, A. Kvashin, A. Laaksonen, K. Lehtipalo, J. Lima, E. R. Lovejoy, V. Makhmutov, S. Mathot, J. Mikkilä, P. Minginette, S. Mogo, T. Nieminen, A. Onnela, P. Pereira, T. Petäjä, R. Schnitzhofer, J. H. Seinfeld, M. Sipilä, Y. Stozhkov, F. Stratmann, A. Tomé, J. Vanhanen, Y. Viisanen, A. Vrtala, P. E. Wagner, H. Walther, E. Weingartner, H. Wex, P. M. Winkler, K. S. Carslaw, D. R. Worsnop, U. Baltensperger and M. Kulmala, Role of sulphuric acid, ammonia and galactic cosmic rays in atmospheric aerosol nucleation, Nature, 2011, 476, 429-433. 20 J. Duplissy, J. Merikanto, A. Franchin, G. Tsagkogeorgas, J. Kangasluoma, D. Wimmer, H. Vuollekoski, S. Schobesberger, K. Lehtipalo, R. C. Flagan, D. Brus, N. M. Donahue, H. Vehkamäki, J. Almeida, A. Amorim, P. Barmet, F. Bianchi, M. Breitenlechner, E. M. Dunne, R. Guida, H. Henschel, H. Junninen, J. Kirkby, A. Kürten, A. Kupc, A. Määttänen, V. Makhmutov, S. Mathot, T. Nieminen, A. Onnela, A. P. Praplan, F. Riccobono, L. Rondo, G. Steiner, A. Tome, H. Walther, U. Baltensperger, K. S. Carslaw, J. Dommen, A. Hansel, T. Petäjä, M. Sipilä, F. Stratmann, A. Vrtala, P. E. Wagner, D. R. Worsnop, J. Curtius and M. Kulmala, Effect of ions on sulfuric acid-water binary particle formation: 2 . Experimental data and comparison with QC-normalized classical nucleation theory, J. Geophys. Res.: Atmos., 2016, 121, 1752-1775.

21 R. Schnitzhofer, A. Metzger, M. Breitenlechner, W. Jud, M. Heinritzi, L.-P. De Menezes, J. Duplissy, R. Guida, S. Haider, J. Kirkby, S. Mathot, P. Minginette, A. Onnela, H. Walther, A. Wasem, A. Hansel and the CLOUD Team, 
Characterisation of organic contaminants in the CLOUD chamber at CERN, Atmos. Meas. Tech., 2014, 7, 2159-2168.

22 A. P. Bateman, M. L. Walser, Y. Desyaterik, J. Laskin, A. Laskin and S. A. Nizkorodov, The Effect of Solvent on the Analysis of Secondary Organic Aerosol Using Electrospray Ionization Mass Spectrometry, Environ. Sci. Technol., 2008, 42, 7341-7346.

23 M. Breitenlechner, L. Fischer, M. Hainer, M. Heinritzi, J. Curtius and A. Hansel, PTR3: An Instrument for Studying the Lifecycle of Reactive Organic Carbon in the Atmosphere, Anal. Chem., 2017, 89, 5824-5831.

24 A. Kürten, T. Jokinen, M. Simon, M. Sipilä, N. Sarnela, H. Junninen, A. Adamov, J. Almeida, A. Amorim, F. Bianchi, M. Breitenlechner, J. Dommen, N. M. Donahue, J. Duplissy, S. Ehrhart, R. C. Flagan, A. Franchin, J. Hakala, A. Hansel, M. Heinritzi, M. Hutterli, J. Kangasluoma, J. Kirkby, A. Laaksonen, K. Lehtipalo, M. Leiminger, V. Makhmutov, S. Mathot, A. Onnela, T. Petäjä, A. P. Praplan, F. Riccobono, M. P. Rissanen, L. Rondo, S. Schobesberger, J. H. Seinfeld, G. Steiner, A. Tomé, J. Tröstl, P. M. Winkler, C. Williamson, D. Wimmer, P. Ye, U. Baltensperger, K. S. Carslaw, M. Kulmala, D. R. Worsnop and J. Curtius, Neutral molecular cluster formation of sulfuric acid-dimethylamine observed in real time under atmospheric conditions, Proc. Natl. Acad. Sci. U. S. A., 2014, 111, 15019-15024.

25 M. Wang, D. Chen, M. Xiao, Q. Ye, D. Stolzenburg, V. Hofbauer, P. Ye, A. L. Vogel, R. L. Mauldin, A. Amorim, A. Baccarini, B. Baumgartner, S. Brilke, L. Dada, A. Dias, J. Duplissy, H. Finkenzeller, O. Garmash, X.-C. He, C. R. Hoyle, C. Kim, A. Kvashnin, K. Lehtipalo, L. Fischer, U. Molteni, T. Petäjä, V. Pospisilova, L. L. J. Quéléver, M. Rissanen, M. Simon, C. Tauber, A. Tomé, A. C. Wagner, L. Weitz, R. Volkamer, P. M. Winkler, J. Kirkby, D. R. Worsnop, M. Kulmala, U. Baltensperger, J. Dommen, I. El-Haddad and N. M. Donahue, Photo-oxidation of Aromatic Hydrocarbons Produces Low-Volatility Organic Compounds, Environ. Sci. Technol., 2020, 54, 7911-7921.

26 M. Xiao, M. Wang, B. Mentler, O. Garmash, U. Molteni, M. Simon, L. R. Ahonen, A. Amorim, A. Baccarini, P. S. Bauer, D. Chen, R. Choi, L. Dada, J. Duplissy, H. Finkenzeller, L. Fischer, X.-C. He, M. Heinritzi, V. Hofbauer, C. Kim, A. Kürten, A. Kvashnin, K. Lehtipalo, H. Mai, V. Makhmutov, S. Mathot, R. L. Mauldin, W. Nie, A. Onnela, T. Petäjä, L. L. J. Quéléver, M. Rissanen, S. Schuchmann, M. Sipilä, D. Stolzenburg, Y. Stozhkov, C. Tauber, A. Tomé, R. Wagner, C. Yan, P. Ye, Q. Zha, J. Curtius, A. Hansel, J. Kirkby, M. Kulmala, R. Volkamer, P. M. Winkler, D. R. Worsnop, N. M. Donahue, C. R. Hoyle, U. Baltensperger, J. Dommen and I. E. Haddad, Second-Generation Chemistry Drives Secondary Aerosol Formation from Aromatic Hydrocarbons, in preparation.

27 N. M. Donahue, S. A. Epstein, S. N. Pandis and A. L. Robinson, A two-dimensional volatility basis set: 1 . organic-aerosol mixing thermodynamics, Atmos. Chem. Phys., 2011, 11, 3303-3318.
28 D. Stolzenburg, L. Fischer, A. L. Vogel, M. Heinritzi, M. Schervish, M. Simon, A. C. Wagner, L. Dada, L. R. Ahonen, A. Amorim, A. Baccarini, P. S. Bauer, B. Baumgartner, A. Bergen, F. Bianchi, M. Breitenlechner, S. Brilke, S. B. Mazon, D. Chen, A. Dias, D. C. Draper, J. Duplissy, I. E. Haddad, H. Finkenzeller, C. Frege, C. Fuchs, O. Garmash, H. Gordon, X. He, J. Helm, V. Hofbauer, C. R. Hoyle, C. Kim, J. Kirkby, J. Kontkanen, A. Kürten, J. Lampilahti, M. Lawler, K. Lehtipalo, M. Leiminger, H. Mai, S. Mathot, B. Mentler, U. Molteni, W. Nie, T. Nieminen, J. B. Nowak, A. Ojdanic, A. Onnela, M. Passananti, T. Petäjä, L. L. J. Quéléver, M. P. Rissanen, N. Sarnela, S. Schallhart, C. Tauber, A. Tomé, R. Wagner, M. Wang, L. Weitz, D. Wimmer, M. Xiao, C. Yan, P. Ye, Q. Zha, U. Baltensperger, J. Curtius, J. Dommen, R. C. Flagan, M. Kulmala, J. N. Smith, D. R. Worsnop, A. Hansel, N. M. Donahue and P. M. Winkler, Rapid growth of organic aerosol nanoparticles over a wide tropospheric temperature range, Proc. Natl. Acad. Sci. U. S. A., 2018, 115, 9122-9127.

29 J. Tröstl, W. K. Chuang, H. Gordon, M. Heinritzi, C. Yan, U. Molteni, L. Ahlm, C. Frege, F. Bianchi, R. Wagner, M. Simon, K. Lehtipalo, C. Williamson, J. S. Craven, J. Duplissy, A. Adamov, J. Almeida, A.-K. Bernhammer, M. Breitenlechner, S. Brilke, A. Dias, S. Ehrhart, R. C. Flagan, A. Franchin, C. Fuchs, R. Guida, M. Gysel, A. Hansel, C. R. Hoyle, T. Jokinen, H. Junninen, J. Kangasluoma, H. Keskinen, J. Kim, M. Krapf, A. Kürten, A. Laaksonen, M. Lawler, M. Leiminger, S. Mathot, O. Möhler, T. Nieminen, A. Onnela, T. Petäjä, F. M. Piel, P. Miettinen, M. P. Rissanen, L. Rondo, N. Sarnela, S. Schobesberger, K. Sengupta, M. Sipilä, J. N. Smith, G. Steiner, A. Tomè, A. Virtanen, A. C. Wagner, E. Weingartner, D. Wimmer, P. M. Winkler, P. Ye, K. S. Carslaw, J. Curtius, J. Dommen, J. Kirkby, M. Kulmala, I. Riipinen, D. R. Worsnop, N. M. Donahue and $\mathrm{U}$. Baltensperger, The role of low-volatility organic compounds in initial particle growth in the atmosphere, Nature, 2016, 533, 527-531.

30 R. C. Reid, J. M. Prausnitz and B. E. Poling, The properties of gases and liquids, McGraw Hill Book Co., New York, NY, 1987.

31 D. S. Wang, C. P. Lee, J. E. Krechmer, F. Majluf, Y. Tong, M. R. Canagaratna, J. Schmale, A. S. H. Prévôt, U. Baltensperger, J. Dommen, I. El Haddad, J. G. Slowik and D. M. Bell, Constraining the response factors of an extractive electrospray ionization mass spectrometer for near-molecular aerosol speciation, Atmos. Meas. Tech. Discuss., 2021, 1-24.

32 Z. An, R.-J. Huang, R. Zhang, X. Tie, G. Li, J. Cao, W. Zhou, Z. Shi, Y. Han, Z. Gu and Y. Ji, Severe haze in northern China: A synergy of anthropogenic emissions and atmospheric processes, Proc. Natl. Acad. Sci. U. S. A., 2019, 116, 8657-8666.

33 U. Molteni, F. Bianchi, F. Klein, I. El Haddad, C. Frege, M. J. Rossi, J. Dommen and U. Baltensperger, Formation 
of highly oxygenated organic molecules from aromatic compounds, Atmos. Chem. Phys., 2018, 18, 1909-1921.

34 O. Garmash, M. P. Rissanen, I. Pullinen, S. Schmitt, O. Kausiala, R. Tillmann, D. Zhao, C. Percival, T. J. Bannan, M. Priestley, A. M. Hallquist, E. Kleist, A. Kiendler-Scharr, M. Hallquist, T. Berndt, G. McFiggans, J. Wildt, T. F. Mentel and M. Ehn, Multi-generation $\mathrm{OH}$ oxidation as a source for highly oxygenated organic molecules from aromatics, Atmos. Chem. Phys., 2020, 20, 515-537.

35 H. Stark, R. L. N. Yatavelli, S. L. Thompson, H. Kang, J. E. Krechmer, J. R. Kimmel, B. B. Palm, W. Hu, P. L. Hayes, D. A. Day, P. Campuzano-Jost, M. R. Canagaratna, J. T. Jayne, D. R. Worsnop and J. L. Jimenez, Impact of Thermal Decomposition on Thermal Desorption Instruments: Advantage of Thermogram Analysis for Quantifying Volatility Distributions of Organic Species, Environ. Sci. Technol., 2017, 51, 8491-8500.

36 S. Schobesberger, E. L. D'Ambro, F. D. Lopez-Hilfiker, C. Mohr and J. A. Thornton, A model framework to retrieve thermodynamic and kinetic properties of organic aerosol from composition-resolved thermal desorption measurements, Atmos. Chem. Phys., 2018, 18, 14757-14785.

37 C. Yan, W. Nie, A. L. Vogel, L. Dada, K. Lehtipalo, D. Stolzenburg, R. Wagner, M. P. Rissanen, M. Xiao, L. Ahonen, L. Fischer, C. Rose, F. Bianchi, H. Gordon, M. Simon, M. Heinritzi, O. Garmash, P. Roldin, A. Dias, P. Ye, V. Hofbauer, A. Amorim, P. S. Bauer, A. Bergen, A.-K. Bernhammer, M. Breitenlechner, S. Brilke, A. Buchholz, S. B. Mazon, M. R. Canagaratna, X. Chen, A. Ding, J. Dommen, D. C. Draper, J. Duplissy, C. Frege, C. Heyn, R. Guida, J. Hakala, L. Heikkinen, C. R. Hoyle, T. Jokinen, J. Kangasluoma, J. Kirkby, J. Kontkanen, A. Kürten, M. J. Lawler, H. Mai, S. Mathot, R. L. Mauldin, U. Molteni, L. Nichman, T. Nieminen, J. Nowak, A. Ojdanic, A. Onnela, A. Pajunoja, T. Petäjä, F. Piel, L. L. J. Quéléver, N. Sarnela, S. Schallhart, K. Sengupta,
M. Sipilä, A. Tomé, J. Tröstl, O. Väisänen, A. C. Wagner, A. Ylisirniö, Q. Zha, U. Baltensperger, K. S. Carslaw, J. Curtius, R. C. Flagan, A. Hansel, I. Riipinen, J. N. Smith, A. Virtanen, P. M. Winkler, N. M. Donahue, V.-M. Kerminen, M. Kulmala, M. Ehn and D. R. Worsnop, Size-dependent influence of NOx on the growth rates of organic aerosol particles, Sci. Adv., 2020, 6, eaay4945.

38 T. Berndt, W. Scholz, B. Mentler, L. Fischer, H. Herrmann, M. Kulmala and A. Hansel, Accretion Product Formation from Self- and Cross-Reactions of $\mathrm{RO} 2$ Radicals in the Atmosphere, Angew. Chem., Int. Ed., 2018, 57, 3820-3824.

39 C. P. Lee, M. Surdu, D. M. Bell, H. Lamkaddam, M. Wang, F. Ataei, V. Hofbauer, B. Lopez, N. M. Donahue, J. Dommen, A. S. H. Prevot, J. G. Slowik, D. Wang, U. Baltensperger and I. El Haddad, Effects of Aerosol Size and Coating Thickness on the Molecular Detection using Extractive Electrospray Ionization, Atmos. Meas. Tech. Discuss., 2021, 1-17.

40 K. C. Barsanti and J. F. Pankow, Thermodynamics of the formation of atmospheric organic particulate matter by accretion reactions-Part 1: aldehydes and ketones, Atmos. Environ., 2004, 38, 4371-4382.

41 J. F. Pankow and W. E. Asher, SIMPOL.1: a simple group contribution method for predicting vapor pressures and enthalpies of vaporization of multifunctional organic compounds, Atmos. Chem. Phys., 2008, 8, 2773-2796.

42 J. Leglise, M. Müller, F. Piel, T. Otto and A. Wisthaler, Bulk Organic Aerosol Analysis by Proton-Transfer-Reaction Mass Spectrometry: An Improved Methodology for the Determination of Total Organic Mass, O:C and H:C Elemental Ratios, and the Average Molecular Formula, Anal. Chem., 2019, 91, 12619-12624.

43 M. Duncianu, M. David, S. Kartigueyane, M. Cirtog, J.-F. Doussin and B. Picquet-Varrault, Measurement of alkyl and multifunctional organic nitrates by protontransfer-reaction mass spectrometry, Atmos. Meas. Tech., 2017, 10, 1445-1463. 